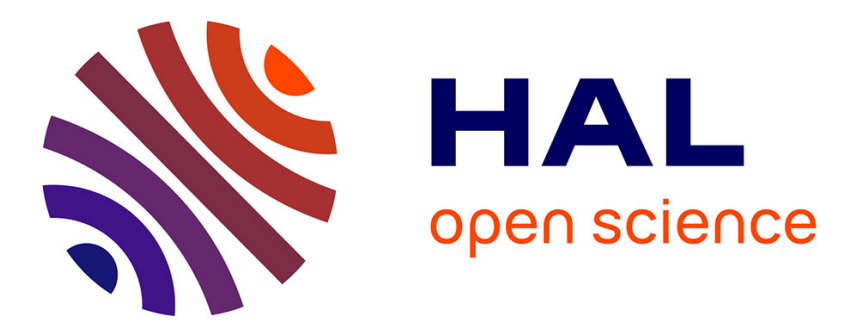

\title{
Multidisciplinary Design and performance of the ONERA Hybrid Electric Distributed Propulsion concept (DRAGON)
}

Peter Schmollgruber, David Donjat, Michael Ridel, Italo Cafarelli, Olivier Atinault, Christophe François, Bernard Paluch

\section{To cite this version:}

Peter Schmollgruber, David Donjat, Michael Ridel, Italo Cafarelli, Olivier Atinault, et al.. Multidisciplinary Design and performance of the ONERA Hybrid Electric Distributed Propulsion concept (DRAGON). AIAA Scitech 2020 Forum, Jan 2020, Orlando, United States. 10.2514/6.2020-0501. hal-03125217

\section{HAL Id: hal-03125217 \\ https://hal.science/hal-03125217}

Submitted on 29 Jan 2021

HAL is a multi-disciplinary open access archive for the deposit and dissemination of scientific research documents, whether they are published or not. The documents may come from teaching and research institutions in France or abroad, or from public or private research centers.
L'archive ouverte pluridisciplinaire HAL, est destinée au dépôt et à la diffusion de documents scientifiques de niveau recherche, publiés ou non, émanant des établissements d'enseignement et de recherche français ou étrangers, des laboratoires publics ou privés. 


\title{
Multidisciplinary design and performance of the ONERA Hybrid Electric Distributed Propulsion concept (DRAGON)
}

\author{
P. Schmollgruber, D. Donjat, M. Ridel, \\ ONERA, the French Aerospace Lab \\ F-31055 Toulouse, France \\ I. Cafarelli \\ ONERA, the French Aerospace Lab \\ F-92322 Châtillon, France \\ O. Atinault, C. François \\ ONERA, the French Aerospace Lab \\ F-92190 Meudon, France \\ B. Paluch \\ ONERA, the French Aerospace Lab \\ F-59045 Lille, France
}

\begin{abstract}
The reduction of carbon emissions is a key objective for the entire Air Transportation ecosystem. At aircraft level, many options are investigated to reduce fuel burn. Within the European Programme Clean Sky 2, ONERA identified Distributed Electric Propulsion as a potential solution to improve significantly the propulsion chain efficiency. In order to mature this technology for transonic cruise speeds, the research concept DRAGON has been defined. Following an initial multidisciplinary assessment, a second set of expert evaluations consolidated the knowledge on Distributed Electric Propulsion and de-risked the challenges associated to its integration on a Large Passenger Aircraft transporting 150 passengers. At mission level, DRAGON and its thrust distribution through an electrical architecture shows interesting benefits in terms of fuel consumption (-7\%) with respect to a reference turbofan aircraft with same EIS on a design range of $2750 \mathrm{~nm}$. Last, it is shown that the evolution of the electrical components regarding not only power densities but also efficiencies will have a strong impact on the technology interest and implementation.
\end{abstract}

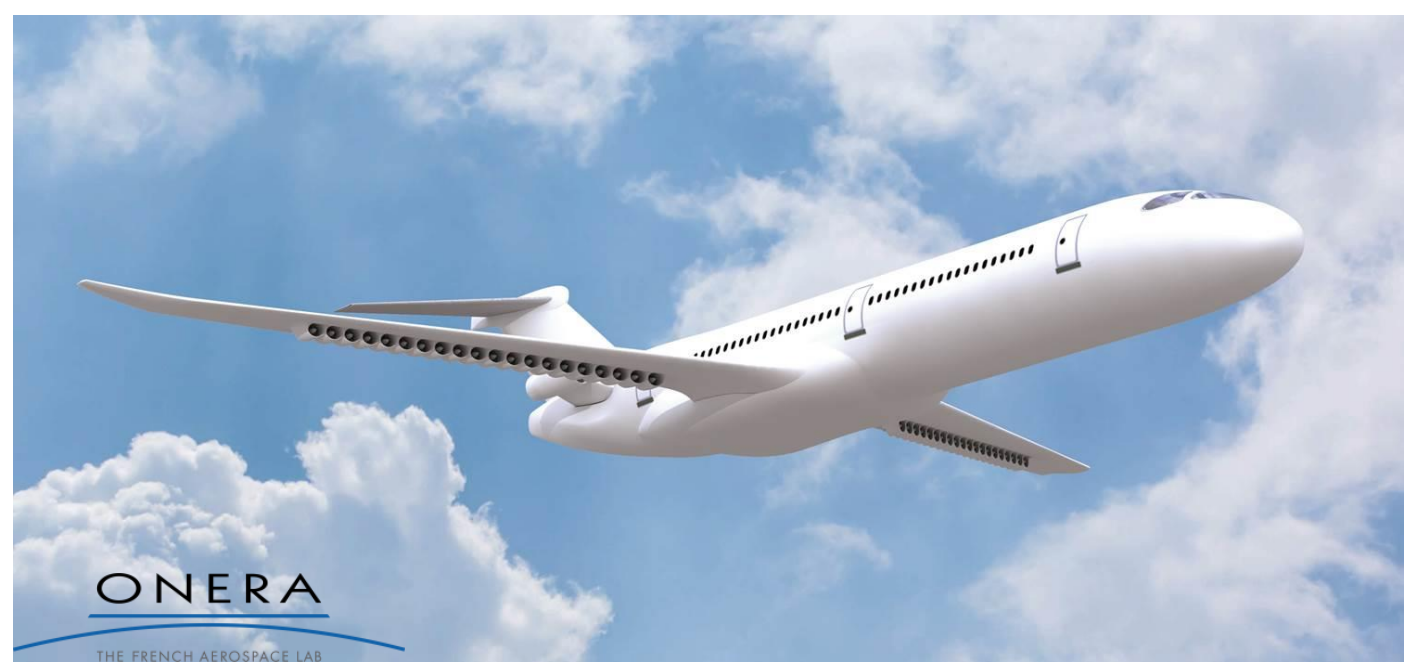

Figure 1 : Illustration of the DRAGON concept (evolution) 


\section{Nomenclature}

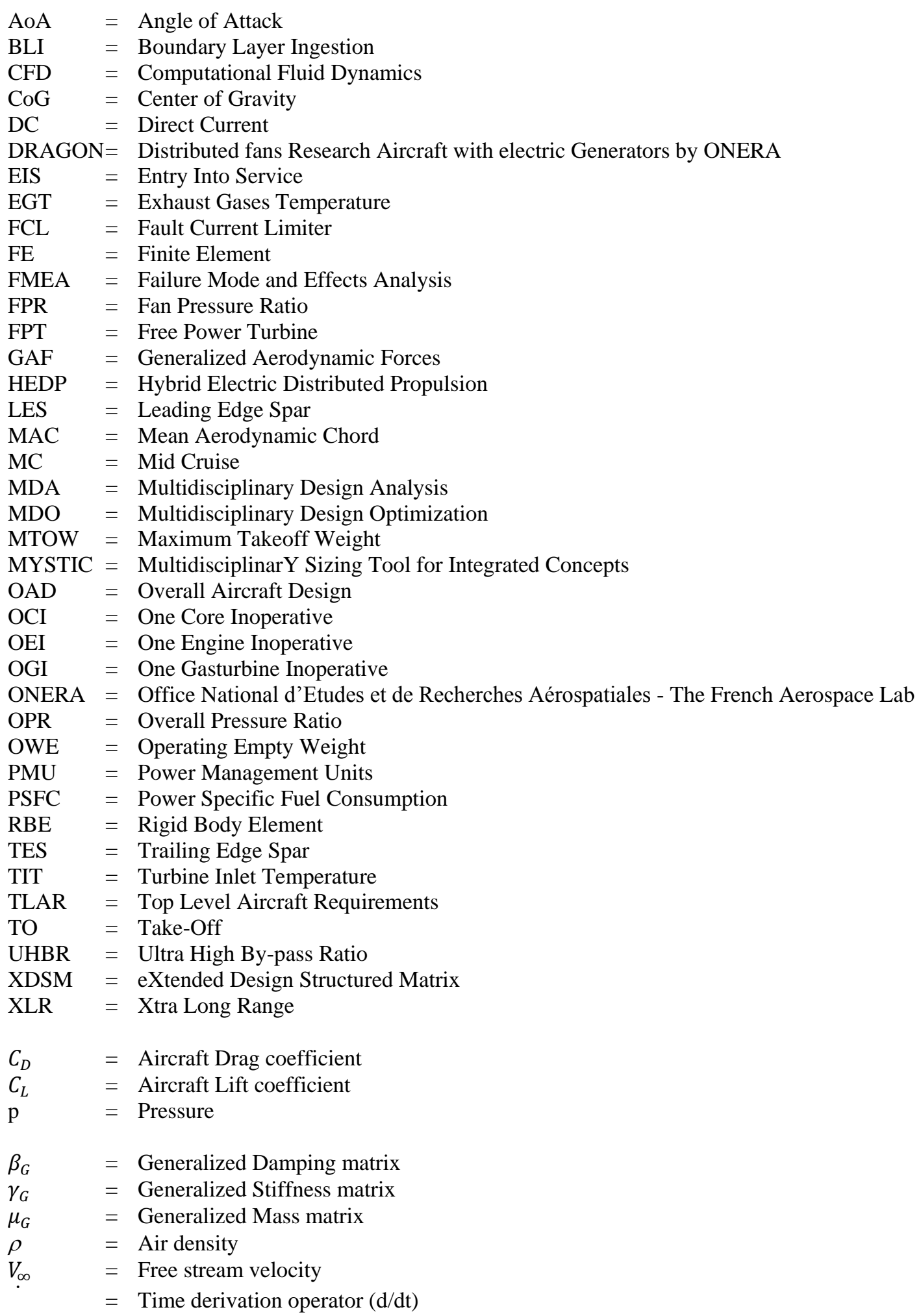




\section{Introduction}

There is a strong social demand ${ }^{1}$ that translates into aircraft manufacturers setting very strong environmental commitments for the next generations of civil transport aircraft in terms of emissions ${ }^{2}$. Considering these long-term goals, the European Programme Clean Sky 2 supports the maturation of different technologies that could be applied in civil aviation in order to achieve greener air transport ${ }^{3}$. For Large Passenger Aircraft, research covers new engines (UHBR and Open Rotor), Boundary Layer Ingestion and Hybrid Laminar Flow among others with the goal of achieving a $30 \% \mathrm{CO}_{2}$ reduction with respect to a 2014 equivalent aircraft ${ }^{4}$.

With various projects carried out in the last years ${ }^{5,6,7}$, hybrid electric propulsion is another potential interesting technology that could be implemented in future aircraft concepts to reduce their carbon footprint ${ }^{8}$. Within ONERA, it is considered that the use of a distributed electric architecture for propulsion is an enabler for increasing aircraft efficiency. Both distributed propellers and distributed ducted fans are possible enablers. While propeller have a better propulsive efficiency than ducted fans, they must fly at slower speeds (not beyond $M=0.7$ ). On the contrary, distributed ducted fans would show the same achievable cruise speed as todays turbofan aircraft. Based on this idea, the research aircraft DRAGON (Distributed fans Research Aircraft with electric Generators by ONERA) has been defined and investigated in 2018. The configuration is characterized by a larger number of distributed ducted fans located along the wing span on the pressure side of the main wing in the vicinity of the trailing edge. In terms of energy chain, the various electric motors are supplied by 2 turbo-electric generators located at the rear of the fuselage. With this overall layout DRAGON allows a detailed understanding of Hybrid Electric Distributed Propulsion potential benefits and drawbacks when applied on a transport aircraft carrying 150 passengers at a transonic cruise Mach number of 0.78 over a mission range that is compatible with airline requirements considering an Entry Into Service (EIS) in 2035. The first results associated to DRAGON presented in $2019^{9}$ indicated potential benefits of such technology with respect to a reference aircraft sized for the same mission range.

However, this initial exploration was based on different assumptions and further studies were required to refine the overall evaluation. The objective of this paper is to present the latest progress on both disciplinary and overall aircraft design aspects of DRAGON.

\section{Disciplinary analyses}

In order to complete reliable trade studies at aircraft level, it is mandatory to increase the knowledge of disciplinary phenomena and systems performance associated to Distributed Electric Propulsion. To this end, off-design studies have been carried out in different departments at ONERA. Information and data gained during these investigations are subsequently taken into account in the Overall Aircraft Design (OAD) or multidisciplinary sizing code MYSTIC (MultidisciplinarY Sizing Tool for Integrated Concepts) ${ }^{10}$. In this chapter, the following 5 topics are detailed:

- Turboshaft performance estimation

- 3D aerodynamics to understand aero-propulsive effects;

- Wing structure analyses;

- Aeroelastic analyses;

- Hybrid Electric Distribution analysis.

\section{A. Turboshaft performance estimation}

As DRAGON is based on two on-board free turbine engines coupled to four electric generators to supply all aircraft's systems, accurate aircraft performance evaluation requires a refined turboshaft's model. Within ONERA, it has been decided to build a model of such turboshaft with the software GasTurb ${ }^{11}$. In order to minimize uncertainties within the model, this gas turbine is based on the characteristics of the CFM's LEAP-1A core.

The natural first step has been the definition of a consistent model of the LEAP-1A engine to be used also in the overall aircraft assessment for the definition of the reference aircraft. In this retro-engineering phase, the design objective was the minimization of fuel consumption in cruise conditions. These simulations were carried out using some reference values for key parameters of the LEAP-1A found in the literature (in particular the few information provided by $\mathrm{CFM}^{12}$ ).

Through basic assumptions and computations at mission level, the initial power request for the turboshaft to be integrated within DRAGON was $7 \mathrm{MW}$ for Mid Cruise (MC) conditions (i.e. Mach=0.78 for an altitude of $10000 \mathrm{~m}$ ) with atmospheric conditions at ISA $+15^{\circ} \mathrm{C}$. In these conditions, an optimization realized with GasTurb ${ }^{11}$ allowed to 
assume the geometry and performances of the DRAGON's turboshaft using a hypothetical 2 spool machine with an additional Free Power Turbine (FPT) working independently from the compression stages. The generic layout of the thermodynamic cycle is shown in Figure 2. The components arrangement is derived from a conventional aeroderived gas turbine hot part comparable to LEAP's core with both multi-stage compressors (booster and high pressure stages) and high pressure turbine linked to the high pressure shaft. A low pressure turbine is introduced as a free power turbine designed to recover entirely the available additional power. The engine design parameters are set up to reflect the 2035 technology ${ }^{13,14,15}$ in order to ensure the highest thermal efficiency. In particular, an advanced compressors stages which generates a high pressure ratio $\Pi$ has been considered and the evolution of the design point's performances in a range of 20:1 to 40:1 has been tested. The temperature at the outlet of compressors (ECT) is limited to $800 \mathrm{~K}^{16}$ while the combustion chamber efficiency is based on the up-to-date architecture for low emissions and in-flight restart purposes. The high pressure turbine uses regulated cooling and un-cooled ceramic matrix stators to increase its efficiency. In this manner, an advanced cooling and metal coating techniques allow to have high gas temperature in high pressure turbine. The maximum Turbine Inlet Temperature (TIT) considered shall not exceed $1800 \mathrm{~K}^{16}$. All rotating component polytropic efficiencies are set to values around 0.91 for both compression and expansion parts. Up to this point, the electric generator is not considered on the thermodynamic machine and conversion efficiency must be added during overall aircraft assessments accounting for the component losses.

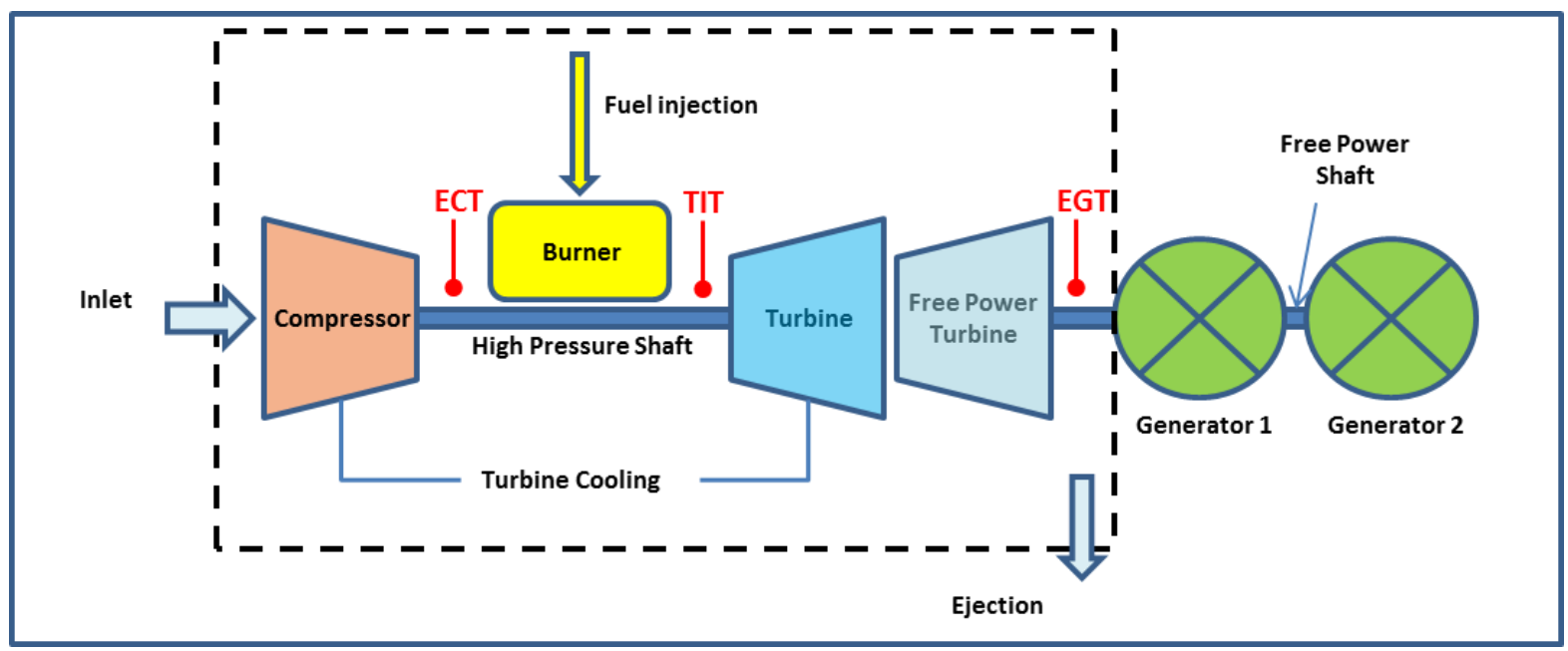

Figure 2 : Engine layout

By assuming $\mathrm{MC}$ conditions at ISA $+15^{\circ} \mathrm{C}$ and the targeted power of $7 \mathrm{MW}$, the optimization process aiming at the minimization of the Power Specific Fuel Consumption (PSFC) leads to a turboshaft characterized by:

- $\quad$ An OPR (i.e. Overall Pressure Ratio) of 37:1;

- A standard massflow rate imposed to $35 \mathrm{~kg} / \mathrm{s}$ in order to insure the available power while limiting the size of gas turbine;

- A cooling massflow set to 3\%;

- An Exhaust Gases Temperature (EGT) equals to $640^{\circ} \mathrm{K}$.

In the end, the turboshaft performance estimations indicate a thermal efficiency of $54.5 \%$ and a PSFC equals to $0.153 \mathrm{~kg} /(\mathrm{kW} . \mathrm{h})$.

A parametric analysis considering the same design leads to a turboshaft power equals to $12.2 \mathrm{MW}$ with a thermal efficiency of $44.2 \%$ for take-off (TO) conditions. For such case, the PSFC reaches $0.189 \mathrm{~kg} /(\mathrm{kW} . \mathrm{h})$. This arrangement leads to an Exhaust Gases Temperature at $710^{\circ} \mathrm{K}$. This reference EGT value will be taken as the maximum allowable for normal engine operating conditions. Even though these assumptions are quite strong, the power map resulting from such evaluation is plotted on Figure 3. 


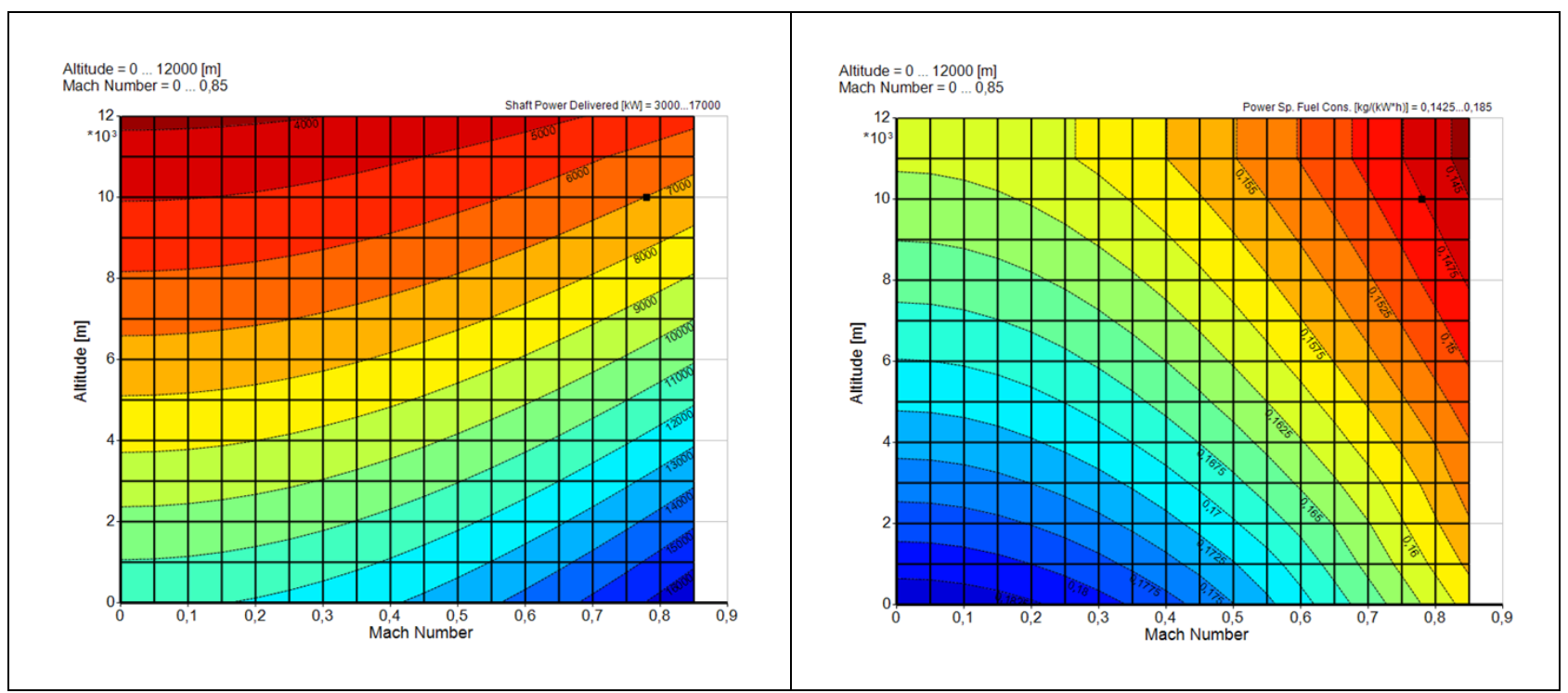

Figure 3 : Maximum power and SFC evolutions according to altitudes and Mach numbers considering simple parametric analysis - The back dot marks the design point (MC)

In order to take into account the real behavior of the turboshaft in the entire flight envelope, one has to build the design cycle of the gas turbine by using standard or specific off-design maps. This approach is quite difficult and needs the complex design of both compressor and turbine geometries as well as performances. In the current gas turbine engine model, off-design cycle calculation is done by adjusting the overall engine massflow rate and compression ratio to ensure that both high and low pressure distributors remain choked. To do so, an iterative process is implemented with a simple Newton solver to try and match the calculated choked section with the reference from the design point. The rotating components efficiencies are updated with a simple ellipsoid approximation accounting for variations in reduced mass flow and reduced rotating speed.

With the performance tables available for both the reference turbofan and the turboshaft dedicated to distributed propulsion, it has been possible to verify the gain offered by the Distributed Electric Propulsion chain in the cruise conditions. Such benefits could be also observed by carrying out a simple efficiencies assessment considering the different propulsive architecture. On one hand, the turbofan has an overall efficiency made of the product between propulsive efficiency and thermal efficiency. For DEP, the overall efficiency corresponds to the product of thermal efficiency, electric components efficiency (from the generator to the electric motor) and fan efficiency.

The method and tools presented in this section enabled to generate 3 complete sets of turboshaft performance level so that various cases could be investigated in the sizing loop with MYSTIC. The 3 turboshafts considered in this study are characterized by an available power in cruise condition of 4, 7 and $10 \mathrm{MW}$.

\section{B. Aerodynamic integration of Distributed Electric Propulsion}

The previous paper ${ }^{9}$ explained how to find a good compromise for the aerodynamic integration of distributed fans on the lower wing. Starting from an ideal but unrealistic configuration, a parametric study was performed using a simplified 2D configuration. After 17 iterations, a good overall behavior was obtained, with a clean upper wing shock, a shocked nozzle, and no flow separation even in front of the air intake (see Figure 4). Because a 2D configuration is unrealistic, and because a pseudo 2D engine channel flow is more difficult to handle compared to a real 3D cylindrical flow, it was decided to move to a first transonic 3D design. 


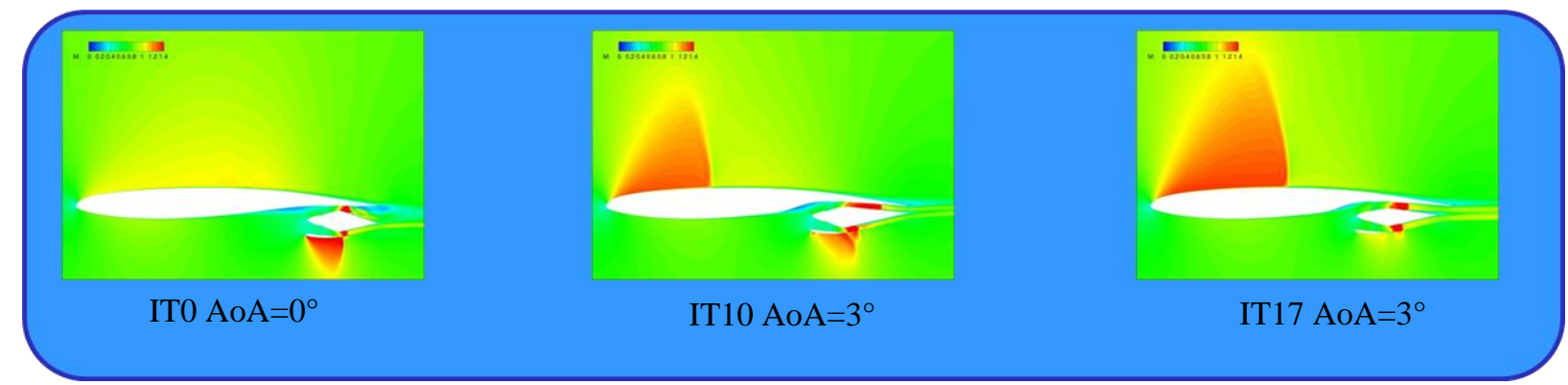

Figure 4 : Previous aerodynamic status based on 2D design. Ideal engine position (left, $A 0 A=0^{\circ}$ ), intermediate iteration for realistic engine position (center), final status (left). All computations are at $M=0.80,35000 \mathrm{ft}$

One challenge when designing a 3D integration of distributed fans is to ensure a periodicity between each engine, without compromising the necessity to design smooth aerodynamic surfaces. Because of the sweep angle, the challenge is even more difficult. This was solved by the idea to perform a "periodic design method", where only one engine is designed, but split in two halves. The split is in the symmetry plane of the engine (Figure 5).

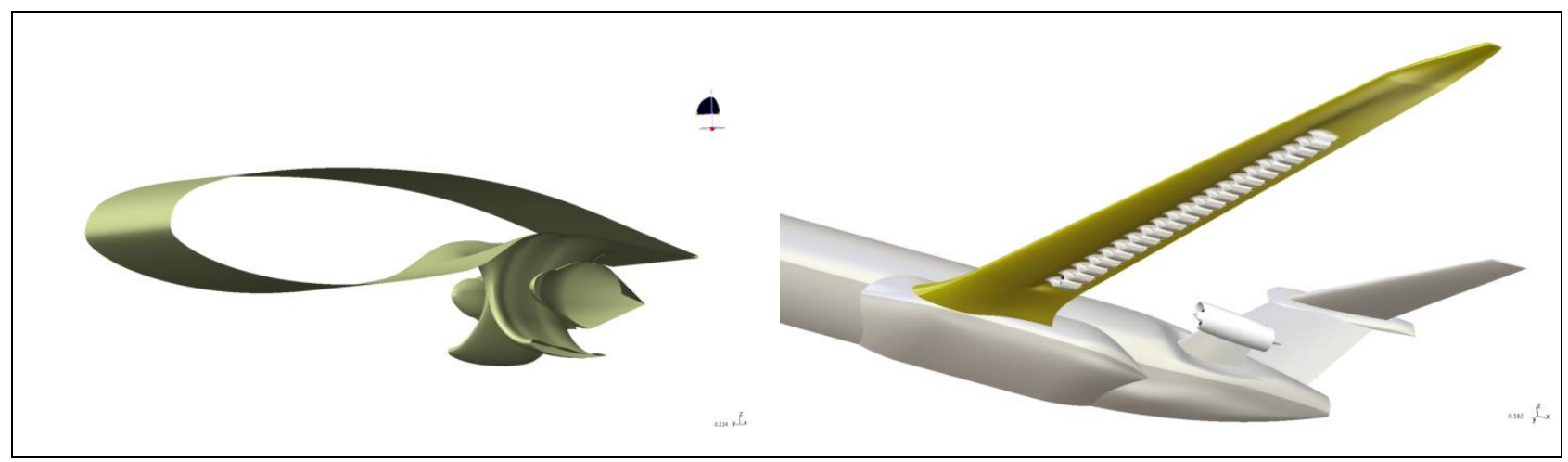

Figure 5 : "Periodic design method" : one engine is designed, split in two halves (left), to ensure geometric periodicity on a wing with sweep angle (right)

Another challenge is to design a transition from a 2D airfoil to a cylindrical section before the inlet, and then to come back to a 2D airfoil after the nozzle, in a very short length. Indeed, any long extension of the air inlet or nozzle surfaces would have detrimental wetted area, which would penalize the configuration. It is also necessary to carefully design the inlet and nozzle section, consistently with the mass flow rate that needs to pass through the engine. For this first design, the target is to simulate a Fan Pressure Ration of FPR=1.1. If successful, it would be possible to generate other designs with larger FPR. The result of the design is illustrated on Figure 6.
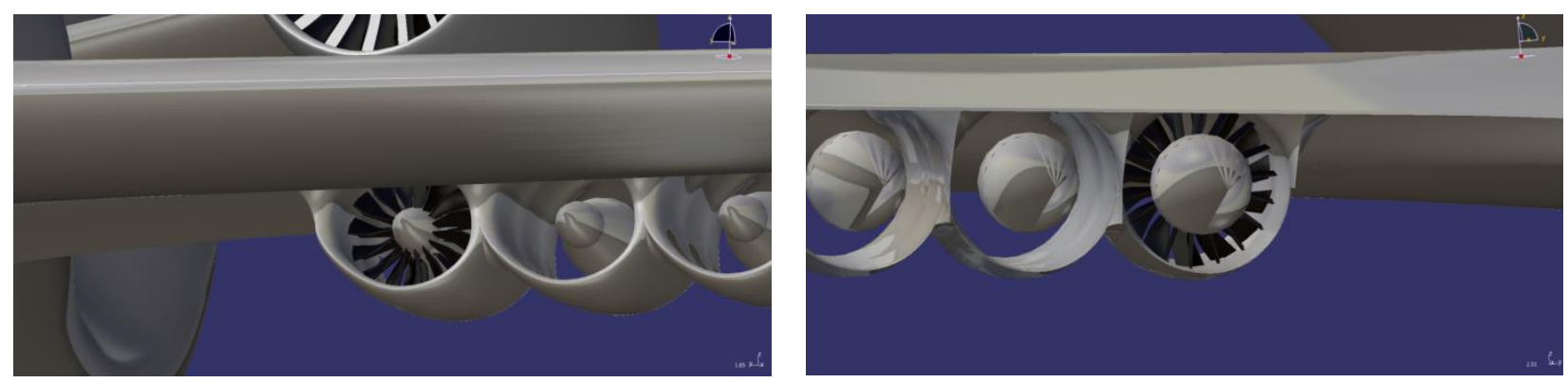

Figure 6 : First DRAGON transonic 3D design, using a "periodic design" method 
That configuration was meshed (only one engine, Figure 7), with IcemCFD. The resulting fully structured mesh has 20 million cells, and the fan is modeled by an actuator disk.

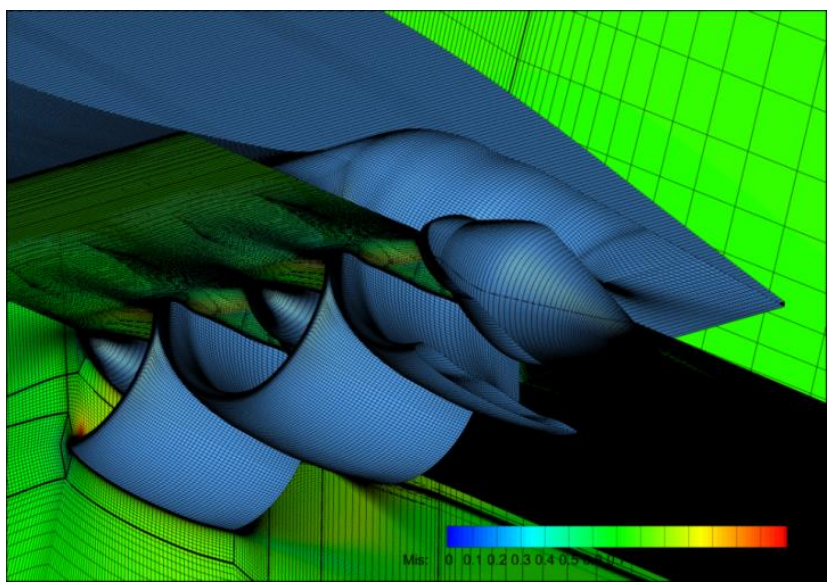

Figure 7 : 3D structured mesh (duplicated for better display, as only 2 halves of one engine are meshed). The fan is modeled by an actuator disk.

A first set of computations was performed using elsA ${ }^{17}$ in steady RANS with the Spalart-Almaraas turbulence model for $\mathrm{M}=0.80,35000 \mathrm{ft}$, $\mathrm{AoA}=3^{\circ}$, and pressure jumps in the actuator disk of $\mathrm{dP}=5000 \mathrm{~Pa}(\mathrm{FPR}=1.13), 7000 \mathrm{~Pa}$ $(\mathrm{FPR}=1.19)$ and $9000 \mathrm{~Pa}(\mathrm{FPR}=1.25)$. The convergence for $\mathrm{dP}=5000 \mathrm{~Pa}$ was very good (Figure 8), and the result led to a too large Lift coefficient $\mathrm{C}_{\mathrm{L}}=0.75$.

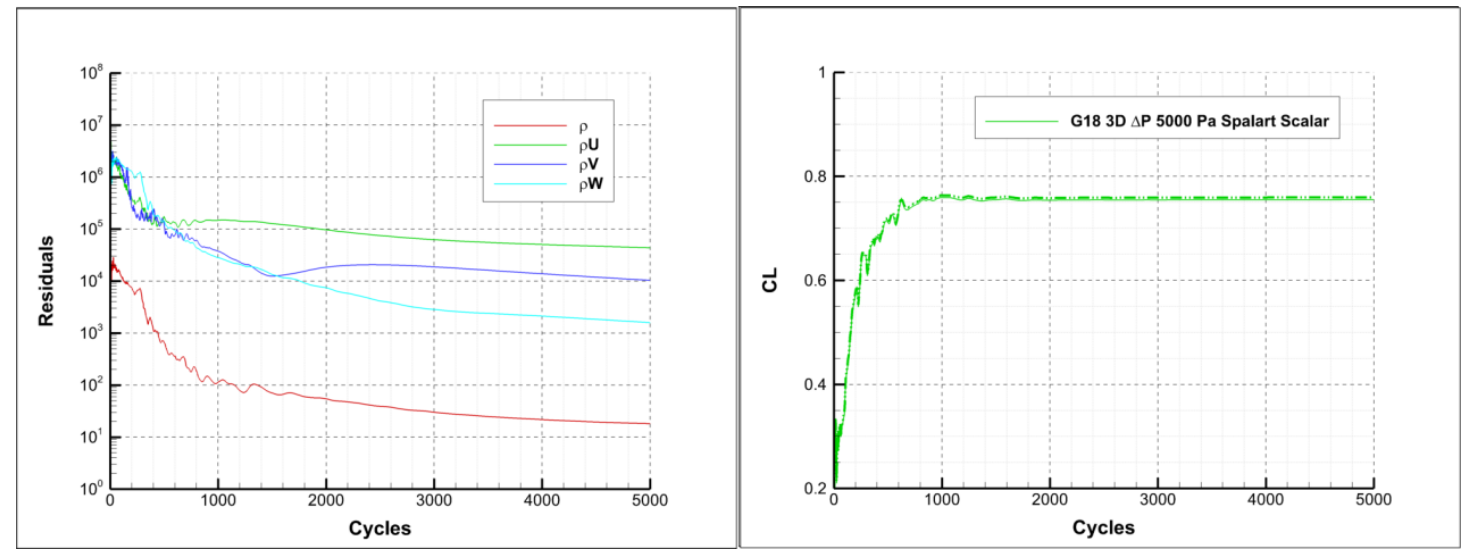

Figure 8 : Convergence of 3D RANS CFD, $\mathrm{M}=0.80, \mathrm{AoA}=2^{\circ}, 35000 \mathrm{ft}, \mathrm{dP}=5000 \mathrm{~Pa}(\operatorname{targeted} \mathrm{FPR}=1.13)$

Convergence for $\mathrm{dP}=7000 \mathrm{~Pa}$ was correct but not good, and the computation with $\mathrm{dP}=9000 \mathrm{~Pa}$ diverged. Consequently, another set of computations was performed at $\mathrm{AoA}=2^{\circ}$ in order to get a lower $\mathrm{CL}=0.60$, closer to the targeted cruise $\mathrm{C}_{\mathrm{L}}$.

On Figure 9 is plotted the isentropic Mach number on the skin, and a slice in the middle of one engine containing the Mach number. The computation, which is only for two halves of one engine, was duplicated for a better view. 


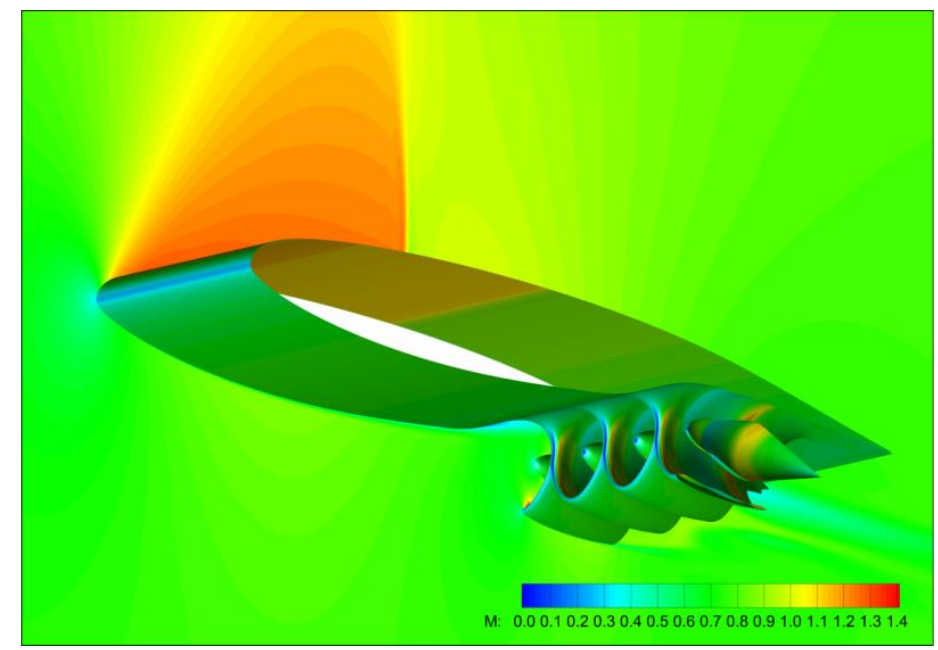

Figure 9 : First CFD result for $\mathrm{G17}$ design, $\mathrm{M}=0.80,35000 \mathrm{ft}, \mathrm{AoA}=\mathbf{2}^{\circ}$, Mach number

At first glance, the overall behavior is satisfactory. The stagnation point on the air inlet is well placed, and the nozzle is gently shocked. This good result is partly due to the choice of having a fan FPR 1.1, which eases the engine design. When comparing this $3 \mathrm{D}$ result to the original 2D target (Figure 10), it can be noticed that:

- The upper wing flow is as expected, though more loaded on the upper wing because of the lower FPR

- The nozzle is separated after the shocked section

- There is a slight overspeed on the lip of the intake (lower part), which is easy to solve.

Except the difference in fan FPR, both computations compare well, which is very promising.
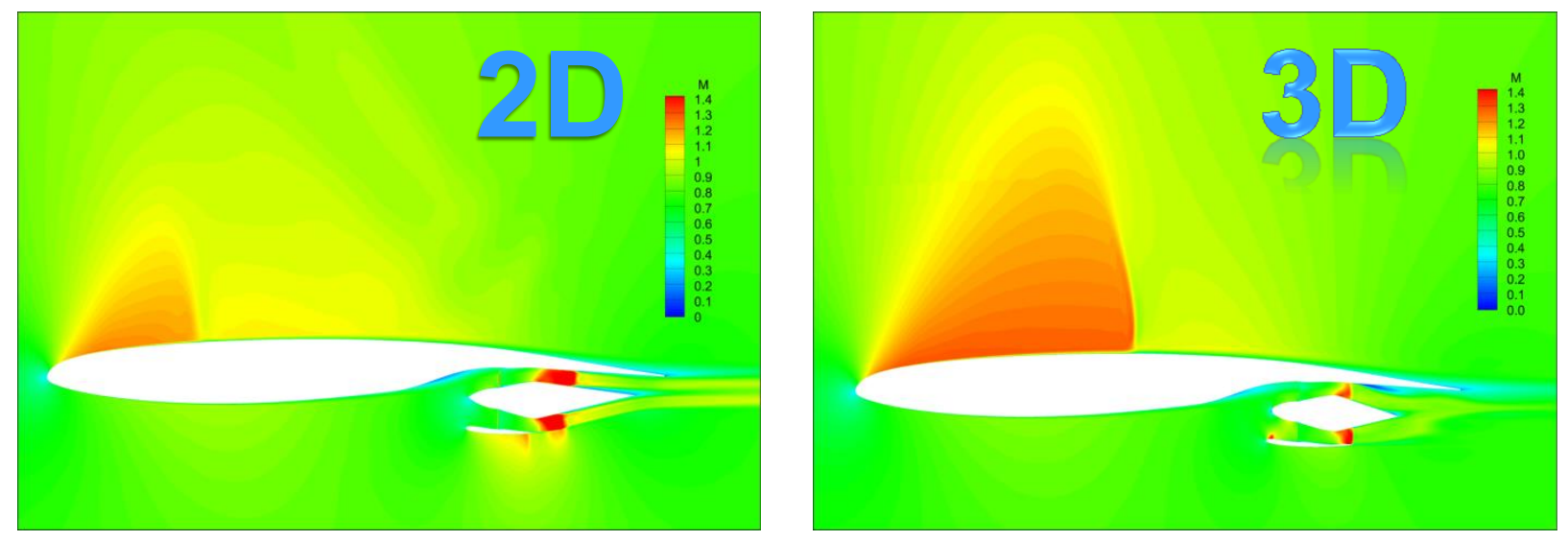

Figure 10 : Comparison of 2D computation (left, FPR=1.3) with 3D computation (right, FPR=1.1), for similar flight conditions $\mathrm{M}=0.80,35000 \mathrm{ft}, \mathrm{AoA}=2^{\circ}$

However, when analyzing the computation more in details (Figure 11), it shows unwanted features. First, the measured $\mathrm{dP} \sim 6500 \mathrm{~Pa}$ which makes FPR=1.18 (instead of 1.13). That was expected, because the available actuator disk is not coded as a target objective. As part of the actuator disk is ingesting the boundary layer of the lower wing (that is BLI), the actuator disk boundary condition is looking for a compromise of pressure jump between the area of freestream total pressure and the area of BLI, leading to a different value than the targeted one. That is not an issue, as far as the computation converges. 


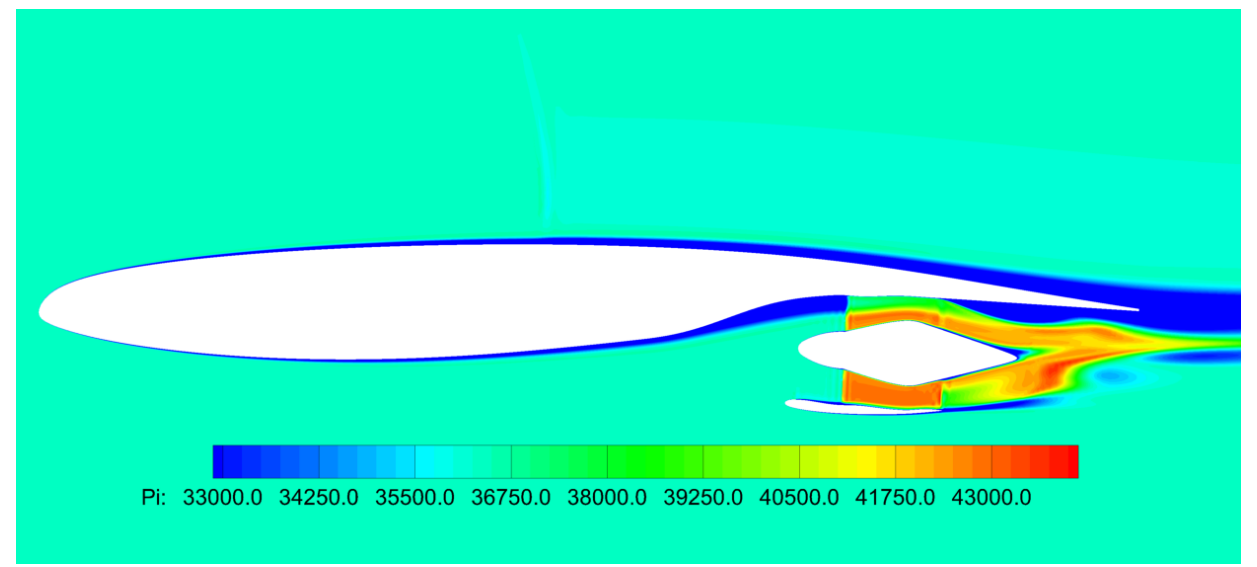

Figure 11 : First CFD result for $\mathrm{G17}$ design, $\mathrm{M}=\mathbf{0 . 8 0 ,} 35000 \mathrm{ft}, \mathrm{AoA}=\mathbf{2}^{\circ}$, total pressure

The second point is the large flow separation in the upper part of the nozzle (the one on the lower wing, concerned by BLI). When looking at the 3D field (Figure 12), that separation is triggered by a combination of curvatures which are not suitable of a transonic nozzle.

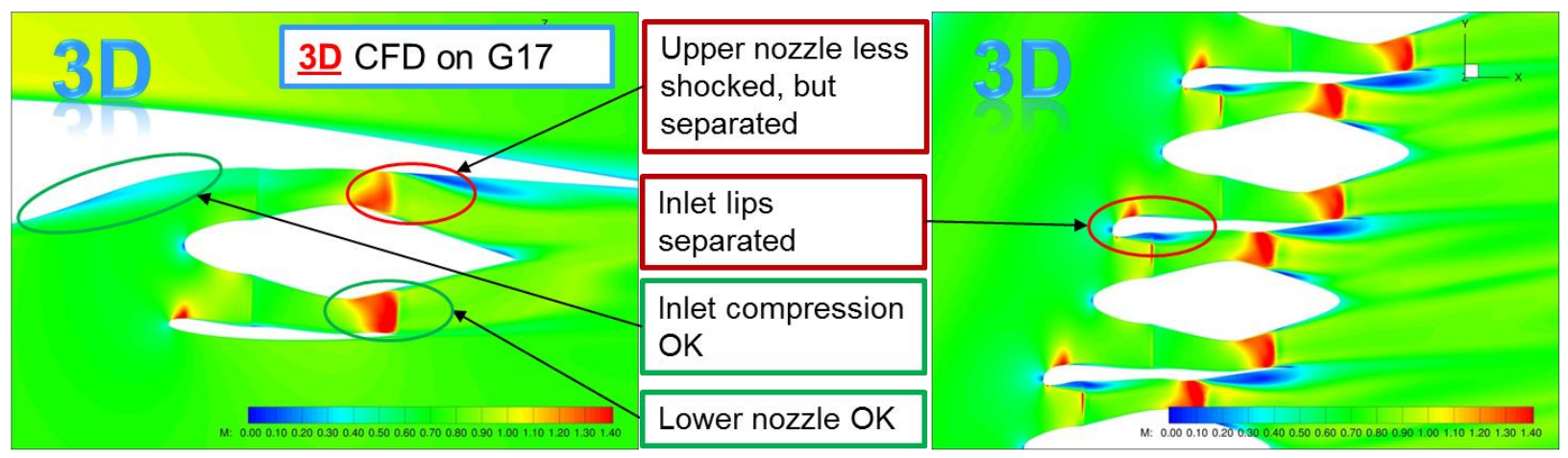

Figure 12 : Illustration of good and bad points (flow separations) on the first design G17

Consequently, two more designs were necessary to start solving those issues. G18 design was focused on solving the issues on the air inlet. As illustrated in Figure 13, the inlet of G18 has no more flow separation or overspeeds. Moreover, the boundary layer of the lower wing does not separate when entering the inlet, which is not obvious when looking at the pressure gradient it must face.

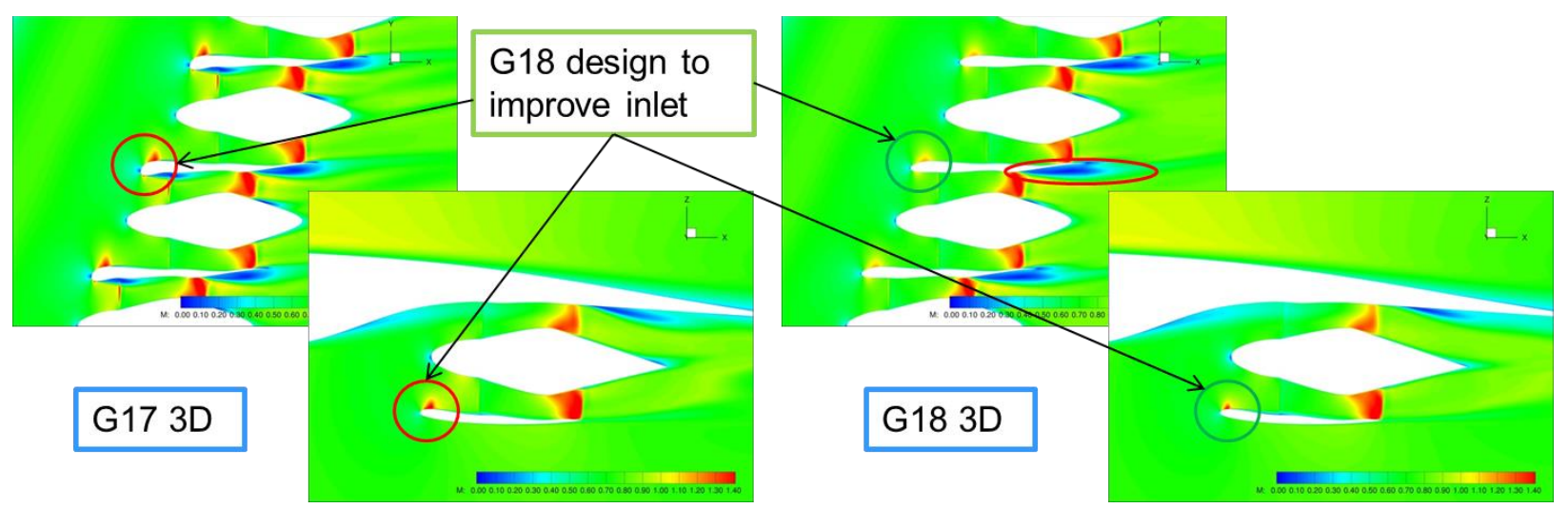

Figure 13 : G18 3D CFD results (right), compared to G17 (left). Purpose is to improve inlet design 
The next step was to cure the nozzle design. In that iterative design process, it was decided to freeze the nozzle plug in the first loop, and to redesign the outer nozzle aeroshapes, which led to G19 design. As displayed in Figure 14, the new design successfully erases the outer nozzle separations, but as feared and expected, the separation moved to the nozzle plug. The next step will be to iterate on the nozzle plug shape, in order to remove the remaining flow separation.

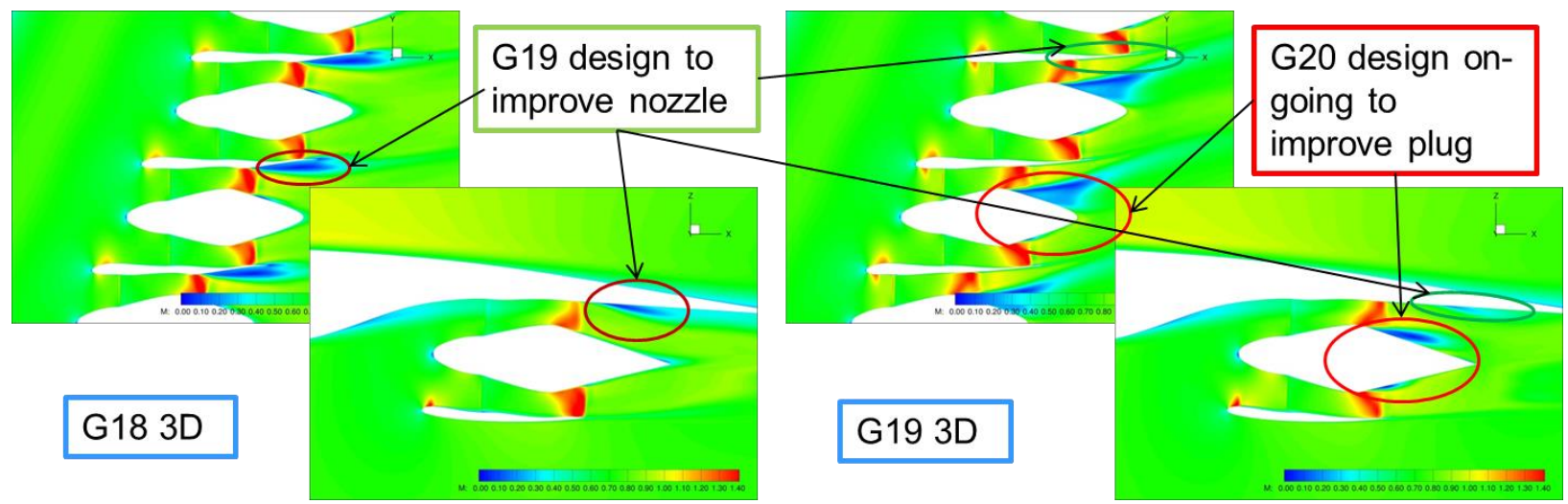

Figure 14 : G19 3D CFD results (right), compared to G18 (left). Purpose is to improve nozzle design. Further work is needed on nozzle plug (on-going work on G20).

\section{Wing structure analyses}

In the 2018 studies ${ }^{9}$, a Finite Element Model of the wing structure has been developed in order to compute more accurately the weight of a wing featuring distributed propulsion. At the time, the design team selected a very rigid structural layout where a secondary structural component was running along the wing span in the vicinity of the trailing edge. The structural analysis showed that such layout was characterized by torsion constraints leading to higher structural mass. In 2019, a more classical approach is chosen so that ducted fans could simply hang on the main wing. The next paragraphs detail all the work that has been carried out to increase knowledge about the wing structure of a DEP Large Passenger Aircraft.

The DRAGON's wing mass is estimated using a calculation code based on a finite element method using threedimensional beam elements. This approach starts with the description of the wing geometry characterization. First, the planform is described by 4 cross sections having the following characteristics: wingspan position $\mathrm{Y}$, airfoil chord relative thickness Rth, and positions of the leading edge (LES) and trailing edge (TES) spars positions along the chord (see Table 7 in Appendix 1). Second, an airfoil approximating DRAGON's wing section is selected and defined in dimensionless coordinates (coordinates are normalized with respect to the chord, see Figure 30 in Appendix 1). To finalize the geometry information, wing segments relying on sections are defined considering also the wing leading edge angle $\phi(25 \%)$ and a dihedral angle $\delta$ (see Table 8 in Appendix 1).

In a second step the material to be used to design the DRAGON wing are selected. Due to electromagnetic compatibility problems, it was decided to use light metallic alloys rather than composite materials. Based on previous experience, the choice is made to use 2 types of aluminium-lithium alloy materials. The $2050 \mathrm{~T} 84$ grade alloy will be used to manufacture the wing skins, ribs and spars (obtained by rolling and aging), while grade 2099 T81 will be used to manufacture the stringers (obtained by extrusion and aging). In parallel, the sizing condition to be considered for the wing sizing corresponds to a $3.5 \mathrm{~g}$ load factor with a safety factor of 1.5 .

The last step consists in developing an automated computation of the electrical components masses that must be distributed within the wing. The calculations take as input the total power to be distributed among a number of electric motors and consider the characteristics of the various elements according to 3 different technology scenarios (see Appendix 2). In this phase, it must be noted that the weight of the cables has been accurately computed and optimized taking into account thermal insulation needs, allowed cross sections and positions of electrical components within the wing.

With this setup, the structure sizing proceeds with the positioning of various components of the propulsion system (converters, cables and electric fans) as shown in Figure 15 (the squares and the circles represent the fan and the 
converters and breakers CoG locations). The mass of the wing is decomposed into primary and secondary structures. The first one is delimited by the wing skins, the leading and trailing edge spars (chord locations specified in Table 7 in Appendix 1) and the ribs (shown in Figure 16). The secondary structures consist of the leading and trailing edges of the wing (shown in blue in Figure 16) to which masses per surface unit have been attributed (typically $20 \mathrm{~kg} / \mathrm{m} 2$ for the leading edge and $30 \mathrm{~kg} / \mathrm{m} 2$ for the trailing edge).

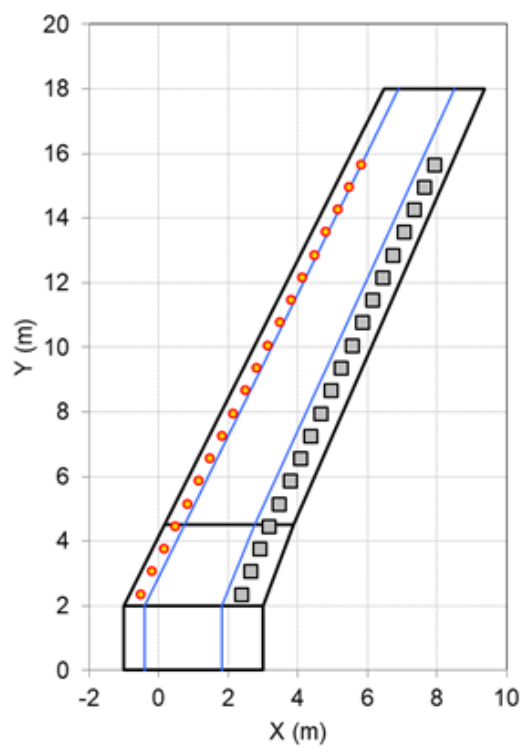

Figure 15 : Location of the different electrical
components on the wing planform

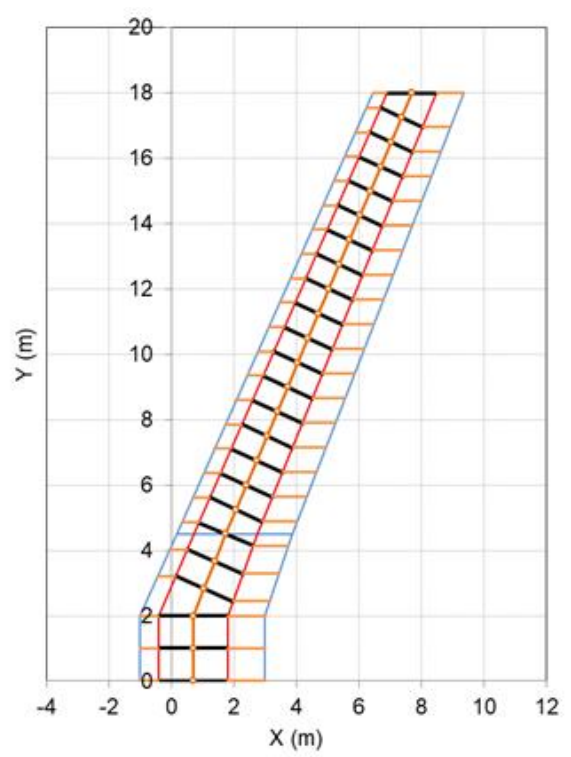

Figure 16 : Wing boxes and associated Finite Element beam model

In the sizing loop, rib and stringer spacing are input data. The wing boxes are delimited by two consecutive ribs and are characterized by their average dimensions (width along the chord, length according to span, and height), used to determine the bending and torsional stiffness and the mass at the centre of each beam element. The threedimensional beam elements ( 6 degrees of freedom per node) are defined by the nodes located at each rib centre (red dots in Figure 16), on the axis passing through wing boxes, assumed to be the elastic axis of the primary wing structure. The secondary structures are considered as non-working structures, ie only their masses are taken into account in the forces acting on the wing. This is also the case of the electric propulsion system components (motors, converters and cables). Afterwards, the distribution of the lift forces is calculated using an in-house Vortex Lattice Method (Figure 17) included in the calculation code, to obtain a more realistic aerodynamic load distribution than a simple elliptic distribution law, particularly in terms of torsional moments acting on the wing.

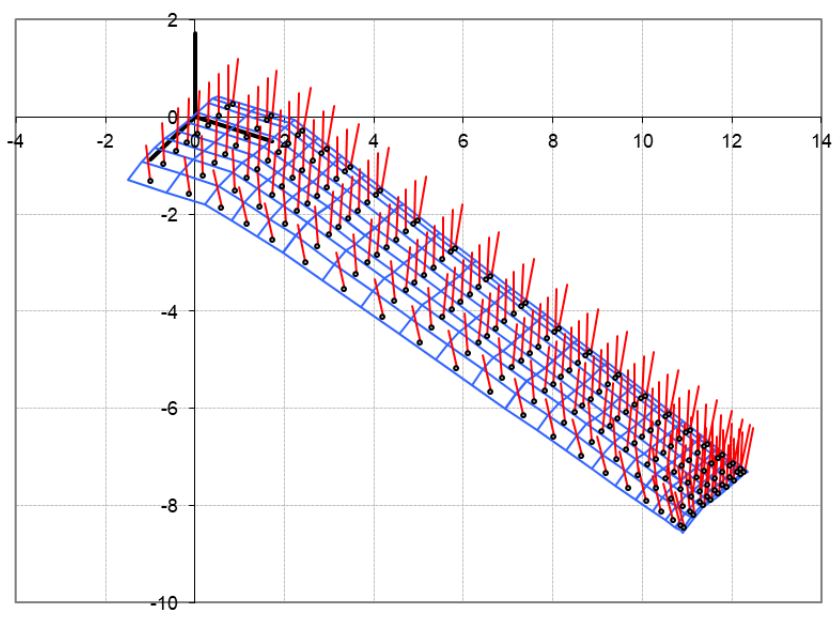

Figure 17 : Vortex lattice mesh of the half wing (the red lines symbolize the normal to each element) 
The aerodynamic values at different spans are then reported on each concerned beam element. Subsequently, a pre sizing procedure is used to roughly estimate the starting values of the various components sizes (skins, ribs and spar thicknesses and stringer sizes).

The final step consists in calculating the beam deformations which are assumed to represent the elastic behaviour of the entire wing box, to determine the forces and moments exerted on each beam element. A new set of thicknesses are then determined to refresh the stiffness and mass of each element to perform again a FE calculation. Since this procedure is iterative, the calculation stops when the mass of the primary structure has converged with a precision factor fixed in advance ( $1 \%$ is used in this study). In most cases, the process converges in two or three iterations, confirming its robustness. Skin thicknesses stringer sizes are determined by an internal optimization procedure which satisfies failure and buckling criteria. Figure 18 shows an example of wing box cross section calculated by the code. The code also checks that each rib has enough space to arrange the path of the different wires harnesses.

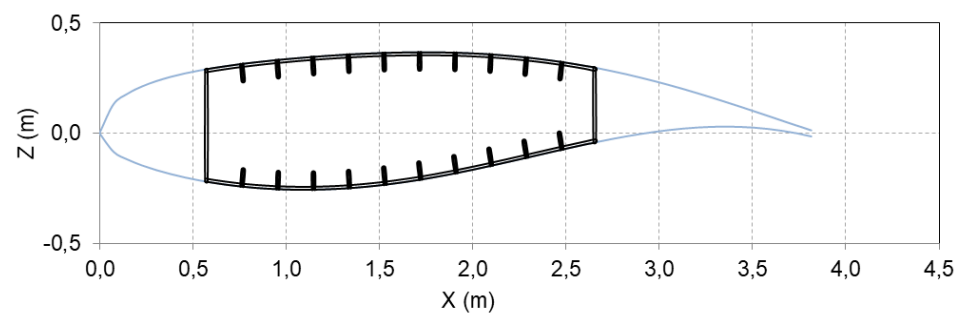

Figure 18 : Illustration of the resulting wing box cross section

With the wing structure sizing code fully operational, various parametric studies have been carried out in order to better understand the key factors that would drive the wing weight. In this work, the reference case for DRAGON features 20 ducted fans connected to electric motors of about $600 \mathrm{~kW}$ considering moderate technology assumptions (see Appendix 2). But naturally, the starting point of the parametric studies has been the sizing of a regular wing based on the classical configuration (1 single turbofan attached to the wing). The comparison of the wing structure mass in both cases shows that the weight distribution along the span in case of distributed propulsion alleviates constraints and results in a lighter wing (about 6\%). With respect to last year's results, no issues related to torsion have been found because of the simpler hanging installation. From the parametric studies, the following observations can be made:

- Impact of technology level

When considering the difference technology scenarios listed in Appendix 2, it must be noted that technological improvements would lead to lighter components. Then, the distribution of these lighter components along the span would translate in higher bending moment due to aerodynamic forces. It is then not surprising to see a decrease of wing structure weight for the negligible evolution scenario $(-2.5 \%)$ and an increase for the significant evolution scenario (1.4\%).

- Impact of total power and the number of engines

For different values of total power $(9,12$ and $15 \mathrm{MW})$, various engine numbers $(10,15,20)$ have been tested considering a regular spacing among them. Looking at the resulting wing weight for the 9 cases, variations with respect to the reference are limited between $-2 \%$ (higher power requirement) and $+2 \%$ (lower power requirement). As for the previous case, higher power demand leads to heavier components that reduce the bending moment.

- Impact of the front spar location

One of the interesting aspects of DRAGON is the possibility to use inverters and their natural heat generation as anti-ice devices. For such objectives, they are place in the leading edge area. However, early assumptions on volume indicate that the front spar should be move rearwards of about 5\% (20\% overall). When sizing this structural layout, simulations indicate an increase of $2 \%$ in wing weight.

- Impact of the wing tip deflection limitation

In DRAGON, one issue that designers have to face is the deformation of the various ducts below the wing because of the wing loading in flight. With this structure sizing code, it has been thus decided to assess the

American Institute of Aeronautics and Astronautics 
wing weight evolution depending on the allowed wing tip deflection. Results are presented in Table 1 here below:

Table 1 : Variation of wing weight for targeted wing tip deflections

\begin{tabular}{|l|c|c|c|c|c|}
\hline $\begin{array}{l}\text { Wing tip } \\
\text { deflection [m] }\end{array}$ & 3.5 & 3 & 2.5 & 2 & 1.5 \\
\hline $\begin{array}{l}\text { Wing weight } \\
\text { variation [\%] }\end{array}$ & -21 & -11 & 0 (Reference) & +16 & +49 \\
\hline
\end{tabular}

From these results, one can see the exponential penalty in weight associated to a structural design limiting the wing tip deflection. It becomes then mandatory to have an integrated and robust design of the wing structure and the ducted fans / electric motors that would be tolerant to wing bending.

\section{Aeroelastic analyses}

In order to refine the aeroelastic behavior of DRAGON initiated in 2018, additional studies have been carried on the updated aircraft version. The following methodology has then been applied:

1. Develop a new FE model of the aircraft with inputs coming from the latest structural sizing design studies;

2. Perform modal analyses on this updated model using the commercial FE tool (MSC Nastran);

3. Input the modal results to an in-house aeroelastic chain in order to derive the aircraft frequencies and dampings for different flight configurations.

Development of a new DRAGON model

The FE model of the aircraft is made of a concentrated fuselage mass linked to both wings. In addition to the airframe mass, the fuselage mass accounts for all the different included items such as the furniture, the payload, the generators, the fuel and its relating tank. Each wing consists of a central spar modelled using a fish bone beam approach: the overall mass of the main wing structure is discretized into lumped masses symmetrically distributed along the wing at several stations. Additional parts considered in a $1^{\text {st }}$ approximation as non structuring from a dynamic point of view (leading edge and trailing edge flaps, slats, connecting central spars) have been added like lumped masses. Finally, the full hybrid propulsion components (electric motors and the corresponding ducted fans, power electronic converters, power cables) have also been inserted like additional masses. This revised version of the DRAGON model is illustrated in Figure 19.

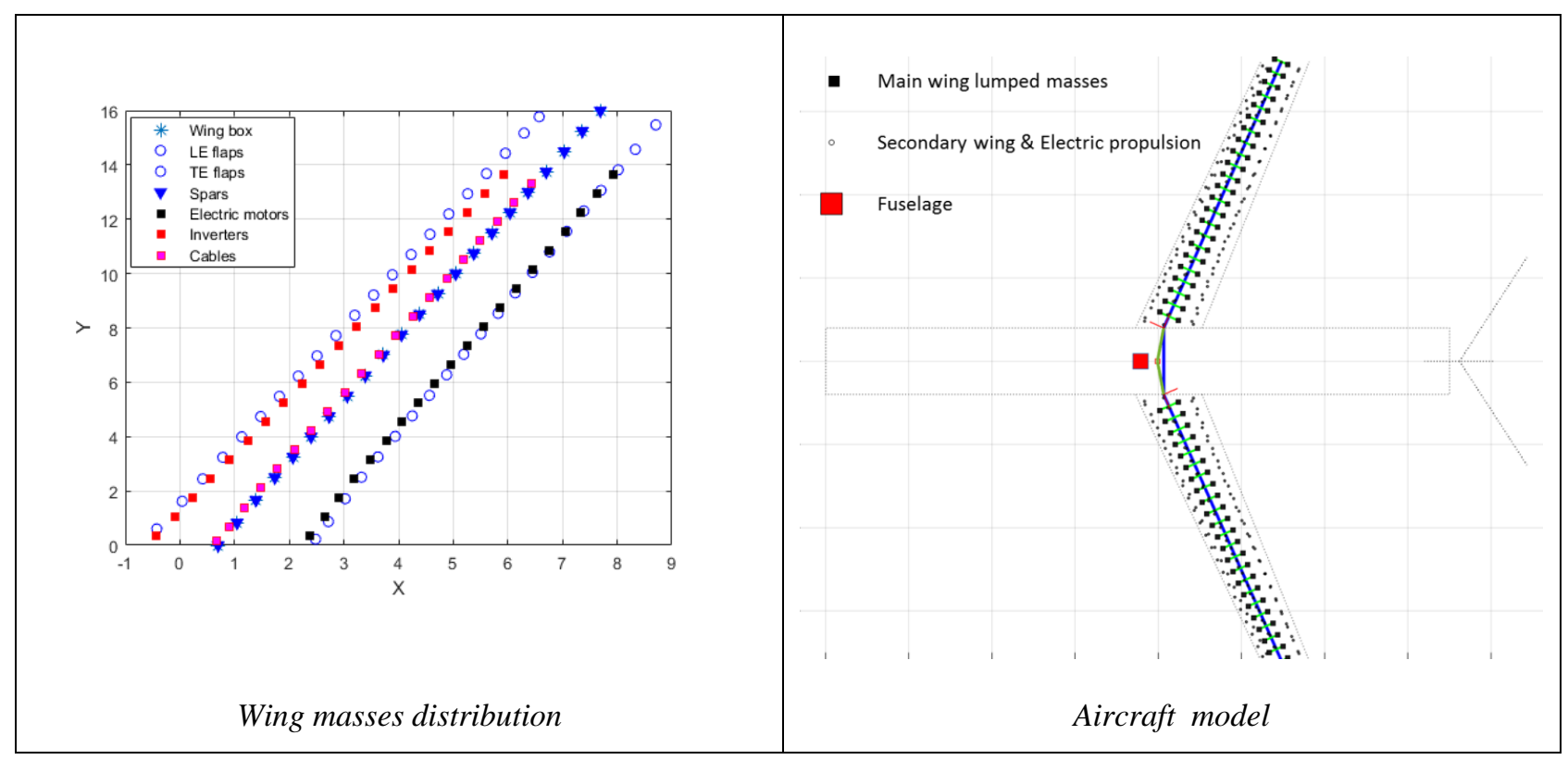

Figure 19 : DRAGON model : reduced spanwise electric propulsion distribution 
Flutter analysis

The overall flutter process is schematically described in Figure 20 and outlined here below ${ }^{9}$ :

- $\quad$ Computation of the aircraft structural normal modes using NASTRAN (SOL 103).

- Creation of an aerodynamic meshing based on the geometry of the wings.

- Projection of the structural normal modes on the aerodynamic meshing through an interpolation process; these fitted modes are then called "aero" modes.

- Computation of the unsteady aerodynamic loads on the aerodynamic mesh (for harmonic oscillations using a panel method namely the Doublet Lattice method; the main inputs in this step are the flight environmental parameters (flight altitude, Mach number) and the frequencies of excitation.

- Computation of the generalized aerodynamic forces (GAF) for the different frequencies of vibration by :

- projecting the loads on the "aero" modal basis

- computing the influence of vibration of each mode on the other modes resulting in a GAF matrix including direct and crossed terms

$$
1 / 2 \rho V_{\infty}^{2} * G A F=\int p n . \varphi d \sigma
$$

where $\mathrm{p}$ is the pressure, $\varphi$ a mode, $\mathrm{n}$ the normal to the surface

$\rho$ the air density and $V_{\infty}$ the velocity

- Flutter analysis using an in-house software named CAPRI (Chaine Aéroélastique de Prévision de la Réponse et des Instabilités) ${ }^{18}$ which solves the coupled "fluid-structure" equations:

$$
\mu_{G} \ddot{q}+\beta_{G} \dot{q}+\gamma_{G} q+\frac{1}{2} \rho V_{\infty}^{2} \times G A F=0
$$

where $\mu_{G}, \beta_{G}, \gamma_{G}$ are the generalized mass, damping and stiffness matrices.

It should be noted that no structural damping was considered in the computations.

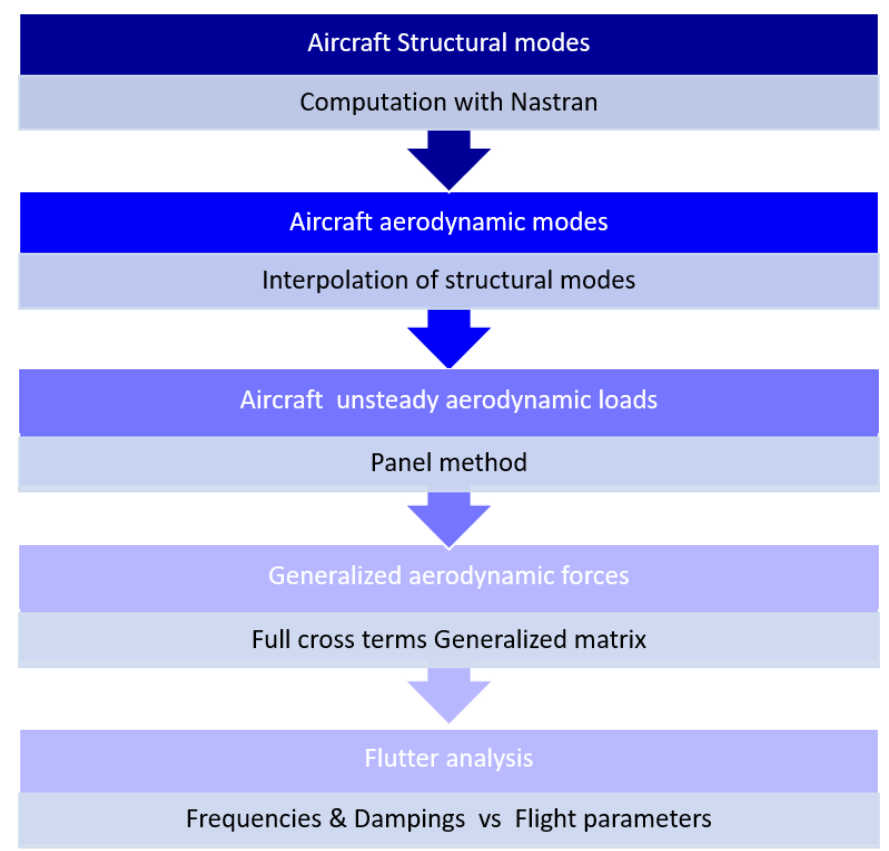

Figure 20 : Flutter computations overall process.

Two main configurations have been considered according to the fan distribution strategy (see Figure 21):

- a configuration (called configuration $\mathrm{n}^{\circ} 1$ ) where the 20 propulsive fans are distributed on the overall wing span;

- a configuration (called configuration $\mathrm{n}^{\circ} 2$ ) where the outer part of the wing doesn't include any fan. (internal spanwise distribution). 


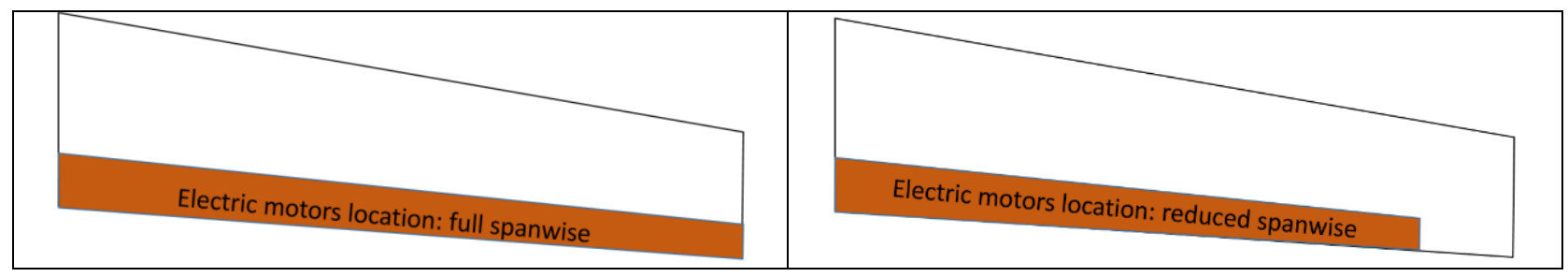

Figure 21 : DRAGON configurations (left : full spanwise motors distribution (conf. $\left.n^{\circ} 1\right)$; right : reduced spanwise distribution $\left(\operatorname{conf}^{\circ} 2\right)$ )

Moreover, some additional arrangements relating to different chordwise locations of the electric propulsion subcomponents such as the cables have been investigated. It should be noted that each new configuration comes from an iterative process including a new structural design loop and hence new wing mechanical characteristics (masses, inertias, stiffnesses, centers of gravity, ...).

The structural aircraft modes with free-free boundary conditions provided by Nastran computations exhibit a usual shape i.e. symmetric and anti-symmetric out of plane bending and torsion components (see Figure 22).

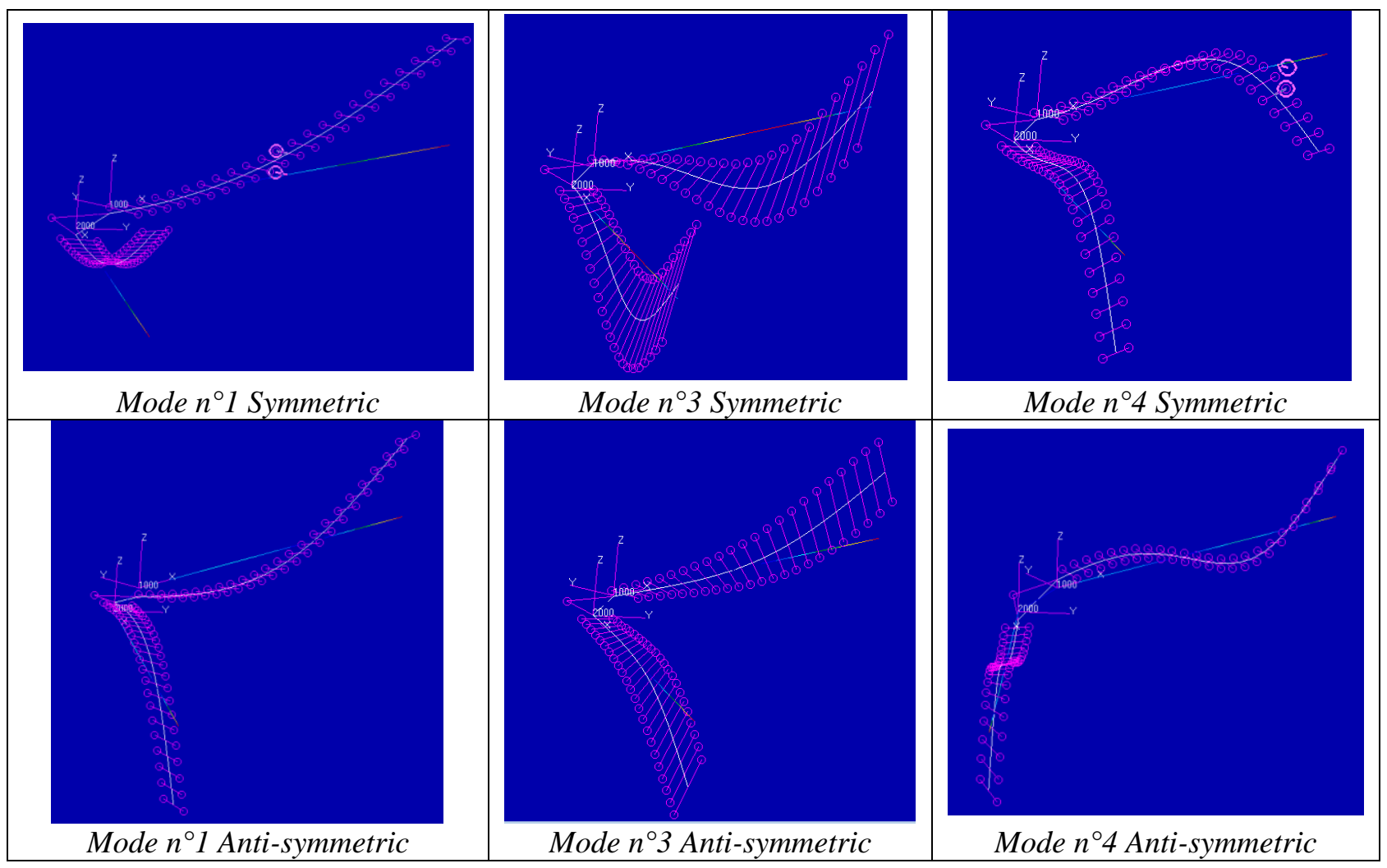

Figure 22 : DRAGON Structural out-of-plane bending and torsion modes. Reduced span motors distribution.

The corresponding "aero modes" used for the flutter computations are displayed in Figure 23. A two directional polynomial interpolation was fitted for each mode according to its relating structural mode shape. 


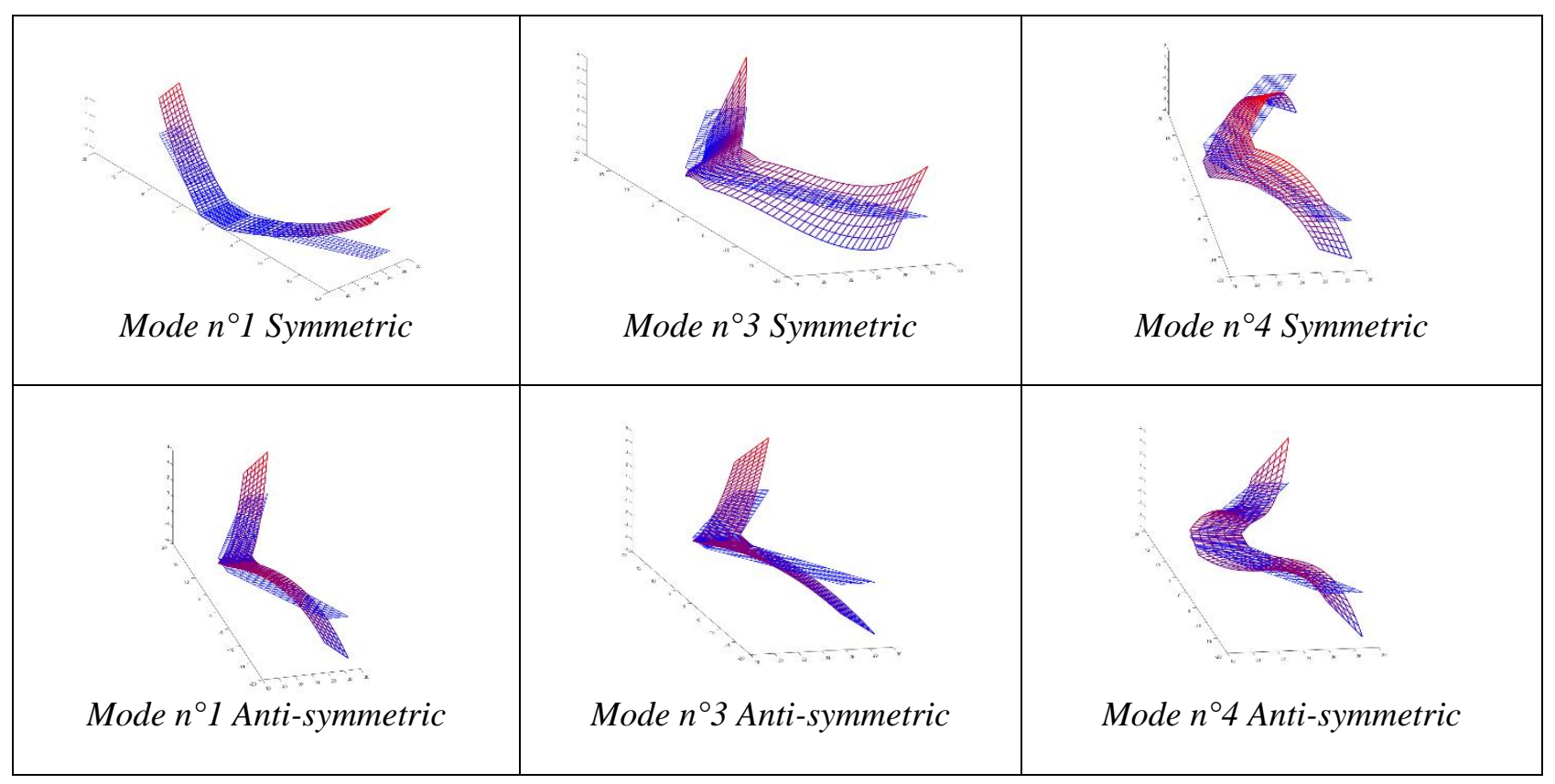

Figure 23 : DRAGON interpolated out-of-plane bending and torsion modes. Full span motors distribution.

The flutter results relating to 3 configurations are displayed on Figure 24 to Figure 26. According to the sign convention of the CAPRI outputs, a modal negative damping corresponds to an unstable mode. Moreover, it is recalled that no structural damping was considered in the calculations. Figure 24 to Figure 25 display, for the configurations $\mathrm{n}^{\circ} 1$ and $\mathrm{n}^{\circ} 2$, the variation of the modal frequencies and dampings with flight speed (up to $\mathrm{M}=0.75$ ) at a cruise altitude of $10000 \mathrm{~m}$ on one hand (left plots) and with altitude at a Mach speed number of 0.7 on the other hand (right plots).

The analyses do not exhibit a flutter risk for the DRAGON configuration: a small instability can be noticed at very low speed and cruise altitude but should be cancelled by the structural dampings. Besides, the overall aeroelastic dampings of the configuration with full spanwise distribution are lower than those with the reduced spanwise distribution; this latter can hence be considered globally more stable.

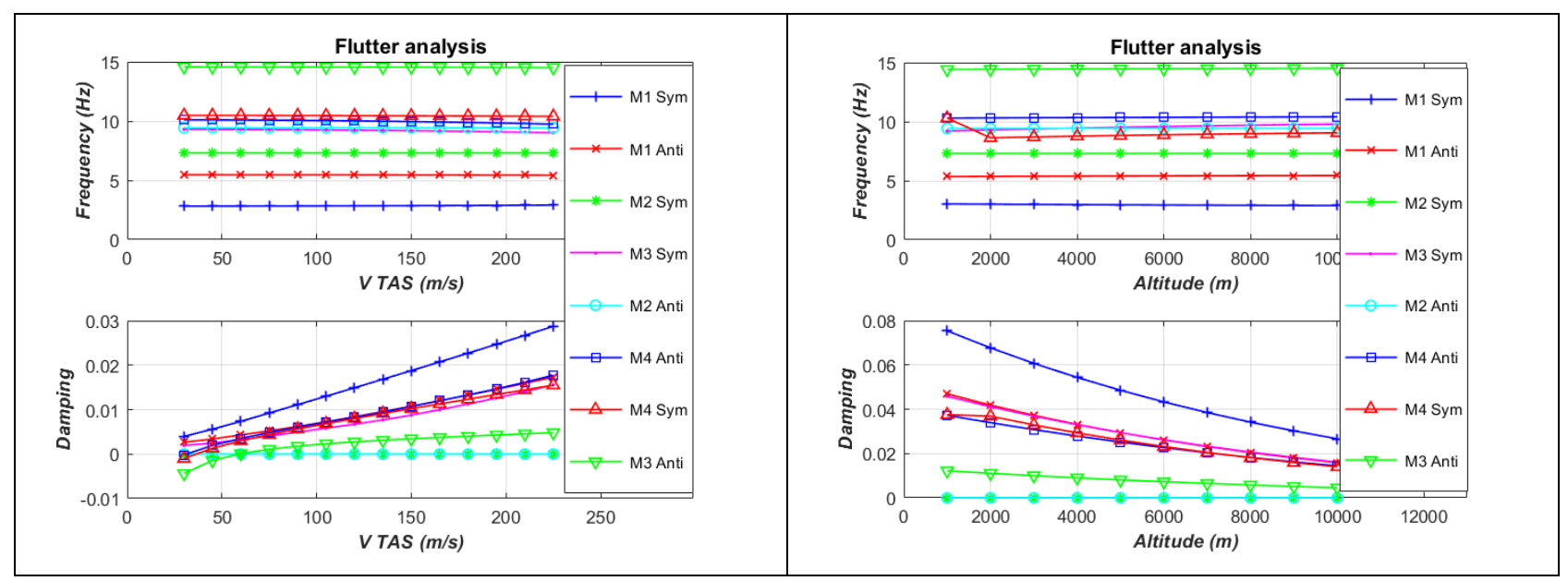

Figure 24 : Flutter analysis of DRAGON configuration 1 (full span motors distribution) 


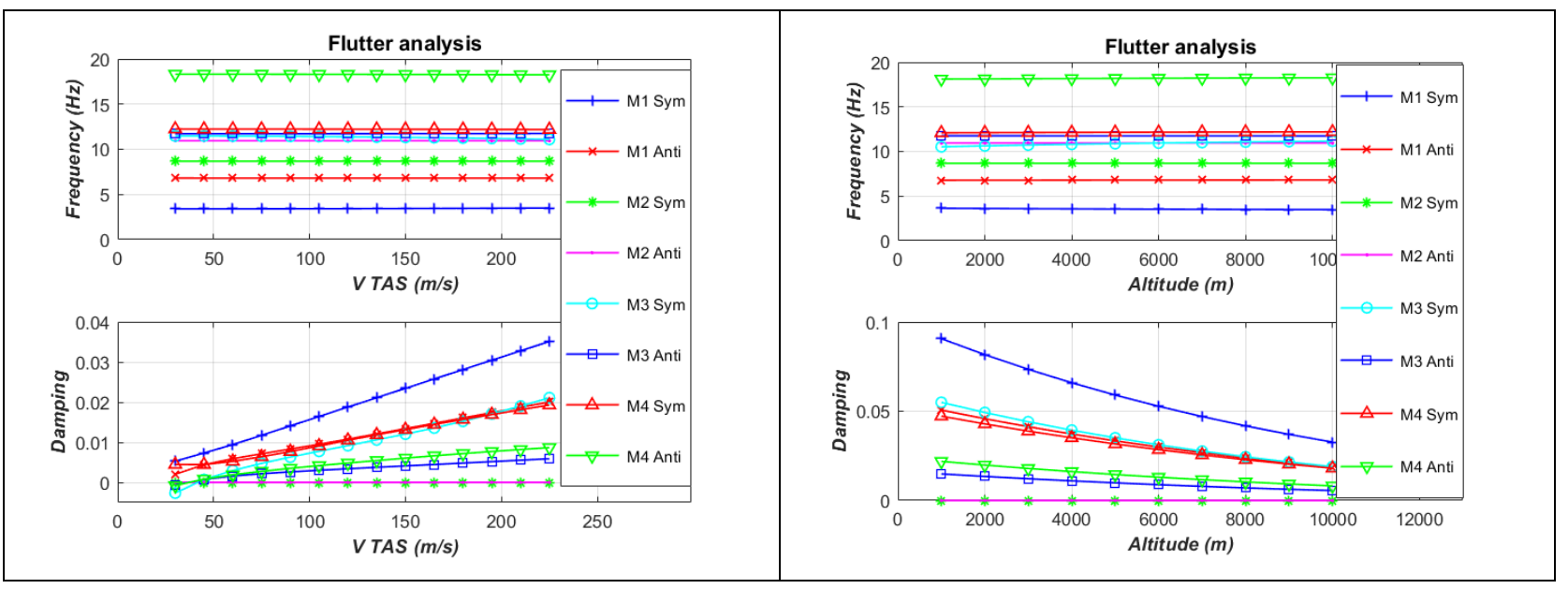

Figure 25 : Flutter analysis of DRAGON configuration 2 (reduced span motors distribution)

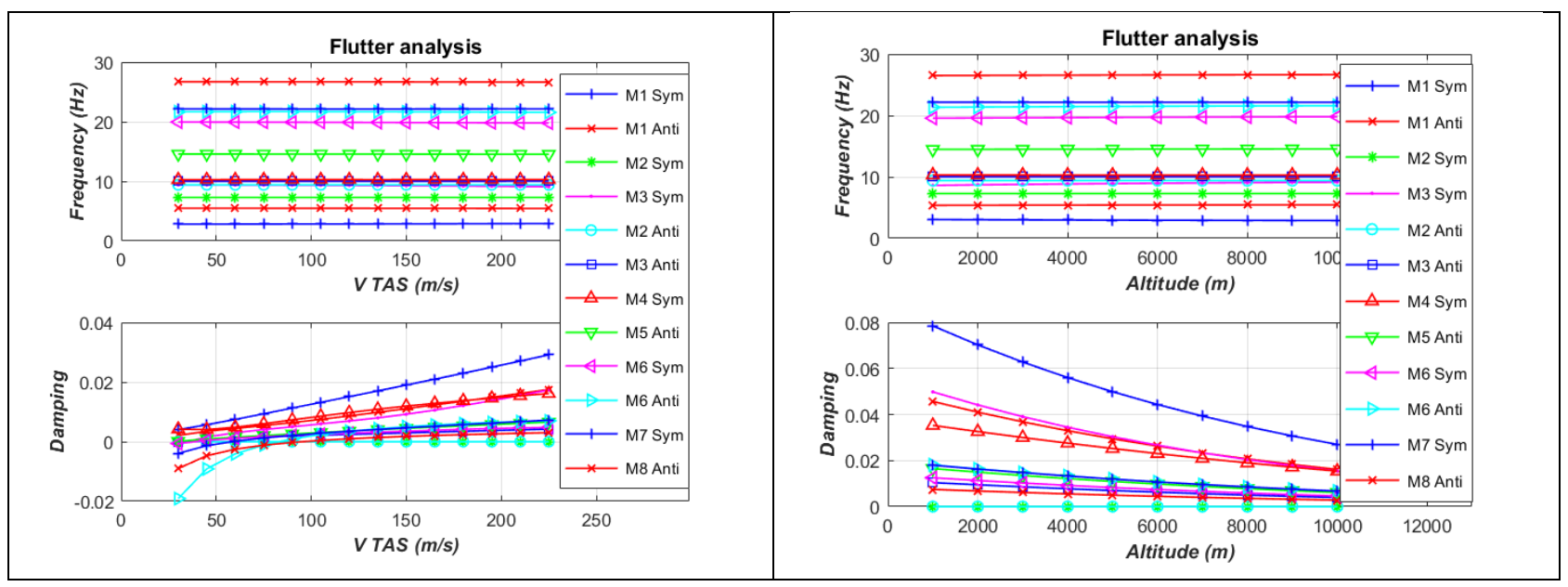

Figure 26 : Flutter analysis of DRAGON configuration 2: power cables located near the trailing edge

In this study, the effect of moving some electric propulsion subcomponents (power cables in this case) from a wing elastic axis nearby location towards the trailing edge (about $70 \%$ chordwise) has been also investigated. The results shown in Figure 26 indicate that such configuration is more destabilizing than the baseline configuration $n^{\circ} 2$, especially at lower speeds. It is therefore advisable to keep as far as possible a well mass balanced layout with respect to the wing elastic axis.

\section{E. Hybrid Electric Distributed Architecture}

In the first design iteration of DRAGON ${ }^{9}$, the selected Hybrid Electric Distributed Architecture was based on two turboshaft engines mounted at the rear, four Power Management Units (PMU) located in the cargo zone and 40 electric ducted fans splitted into four clusters of 10 units each. A preliminary safe distributed electrical architecture has been defined to take into account mainly the loss of one turboshaft (see Figure 27).

During the second design loop, a trade-off analysis on the electrical architecture is performed to evaluate the electrical systems characteristics (unit power) considering failure scenarios ${ }^{19}$. Indeed, the redundancy choices of electrical systems allow an optimization of their power and weight. In Figure 11, a preliminary cross-redundant architecture is proposed.

This solution is based on four embedded generators (two for each turboshaft). Each generator is connected to two propulsion buses, and one turboshaft, driving two generators, provides power to the four propulsion buses. Under 
this configuration, a single engine can support all Electric Ducted Fans by providing power to all of the buses. More important, such layout provides a certain redundancy that will limit oversizing of components in case of failure. The next steps to be completed are a detailed weight and volume estimation of the overall electric architectures together with a reliability analyses through a FMEA approach.

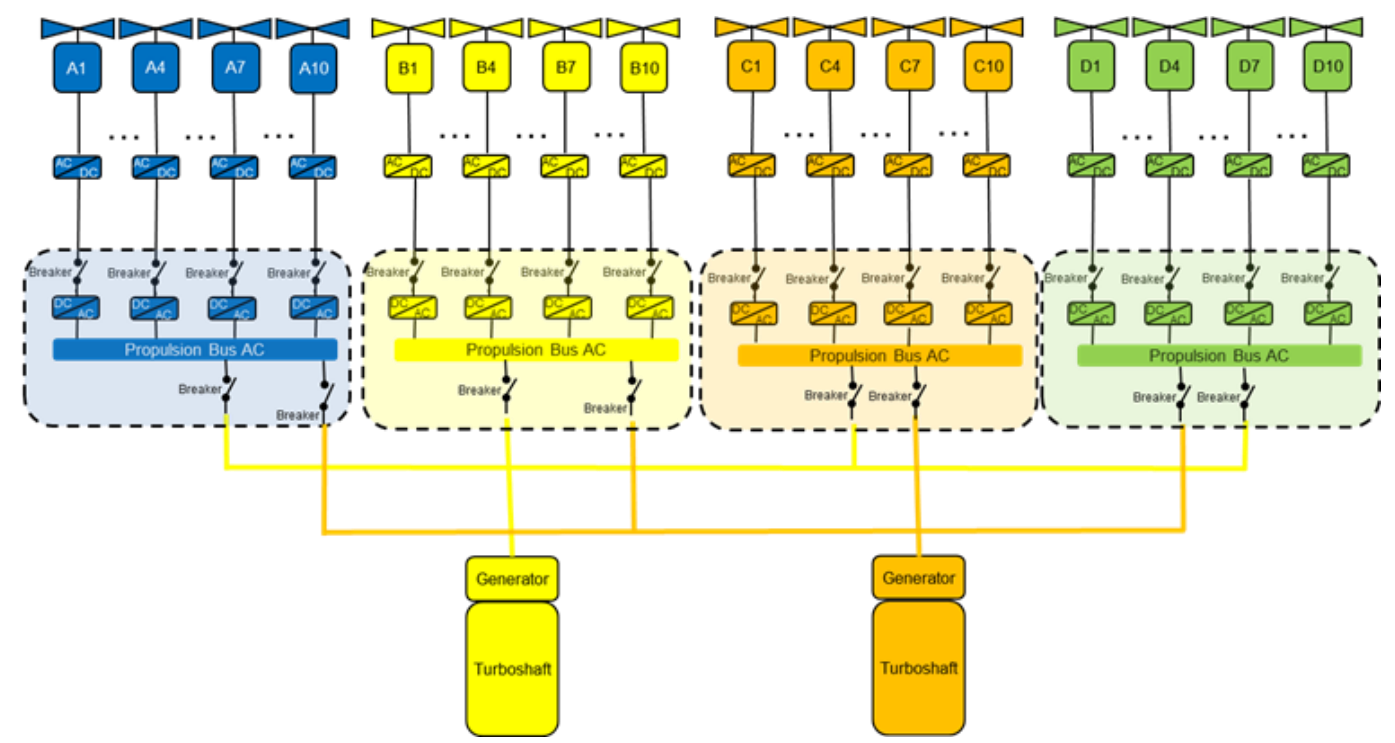

Figure 27: Preliminary safe distributed electrical architecture

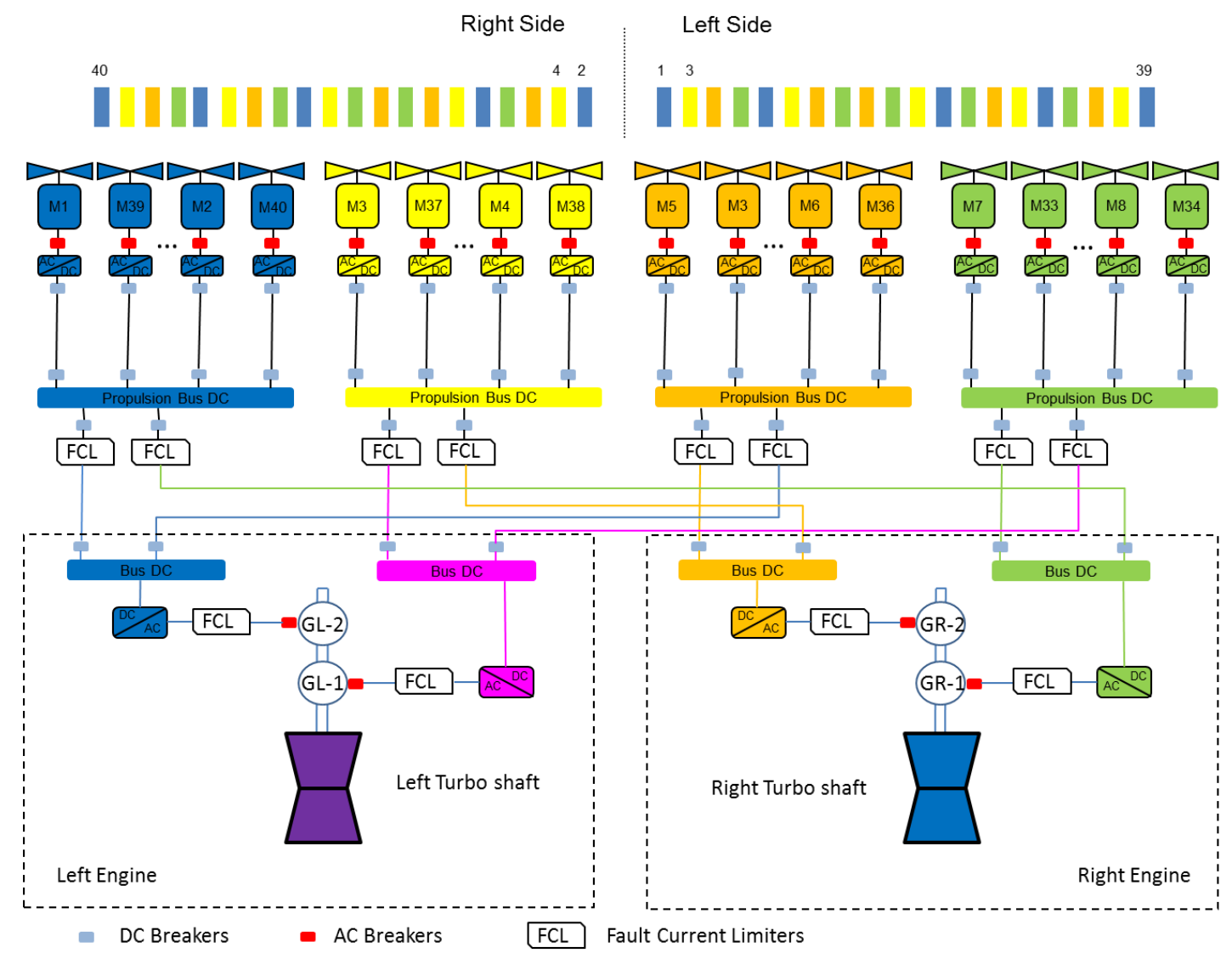

Figure 28: Preliminary Cross-redundant Architecture Diagram 


\section{Overall Aircraft Sizing and Synthesis for DRAGON}

The DRAGON overall aircraft sizing and synthesis performed in 2018 at ONERA showed potential gains of the DEP technology for a short range design mission". A review of the fuel consumption during the mission segment highlighted a lower consumption during climb while in cruise, the classical turbofan was more efficient. Such result is surprising as the basic idea of Distributed Electric Propulsion is to have a more efficient propulsion system for cruise. In addition, studies performed by ESAero on the ECO 150-300 presented in January $2019^{7}$ highlighted benefits on a $3500 \mathrm{~nm}$ design mission for a turbo-electric distributed propulsion aircraft with respect to an equivalent EIS classical turbofan configuration. In this case, even if the propulsion system leads to higher fuel consumption, the benefits over the mission are obtained because of a very high lift-to-drag ratio (resulting from a detailed high-fidelity aerodynamic optimization). These differences showed that more detailed investigations had to be performed to assess in a reliable way the assets and drawbacks of Distributed Electric Propulsion when integrated on a Large Passenger Aircraft airframe. In the next sections, the aircraft sizing and synthesis of DRAGON is detailed. With respect to the previous overall design loop, this analysis includes the turboshaft performance database presented in section II.A. and refined failure cases to be considered.

\section{A. The DRAGON sizing process}

To size and assess the performances of DRAGON over a given mission, ONERA uses its internal tool MYSTIC ${ }^{10}$ that is fully compatible with the software FAST (Fixed wing Aircraft Sizing Tool) developed by ONERA and ISAESupaero. With respect to hybrid electric propulsion, the design process has been revised to evaluate a transport aircraft using batteries (for zero emissions operations in the vicinity of the airport) and blown wings ${ }^{20}$. This same process has been tailored in MYSTIC for the assessment of DRAGON taking into account the new turboshaft model (section II.A) as well as information from the aerodynamics assessment (section II.B) and the wing structure computations (section II.C) associated to the below-the-wing ducted fans installation.

The DRAGON sizing process can be represented using the XDSM standard ${ }^{21}$. In this standard, the disciplines have been identified by a green rectangle, whereas the orange circle represents a loop; grey and white blocks are I/O and intermediate variables. The main workflow is identified by the black line, and the grey lines represent the data sharing. Illustrated in Figure 31 of Appendix 3, the complex data flow to be considered for the sizing of an hybrid electric aircraft is highlighted by the important number of grey lines, connecting the various disciplinary / system modules. The associated algorithm is described here below (numbering refers to Figure 31 of Appendix 3).

\footnotetext{
0 . Initiator. This block initializes the problem and found a first estimate of the aircraft parameters. while

1. Initialize the MDA loop.

2. Size the components of the DEP chain, based on power levels from previous iteration.

3. Size the wing, in order to satisfy the criterion of $C_{L \max }$ in approach configuration.

4. Compute an initial geometry, based on a few set of entries per component (such as aspect ratio, sweep or taper ratio).

5. Resize the geometry, iteratively changing the wing and landing gear position and the tails, in order to satisfy stability criterion on static margin.

6. Compute the trimmed polars at low and high speed, considering the geometrical output of step 5 .

7. Compute the detailed mass breakdown, based on a revised version of the French norm $2001 / \mathrm{D}^{22}$ to take into account mass of hybrid propulsion system.

8. Compute the trajectory of aircraft on a given design mission, using the data from step 6 and 7 . The aircraft is schematized as a point, and the time step approach is used for each mission leg.

9. Check the convergence. The driven parameter for the convergence is the operating weight empty OWE, which is estimated at step 7 (Mass breakdown) and step 8 (Performance): at convergence, these two values must match. In practice, it is required that the relative difference between the two is below $0.05 \%$; if not, update the MTOW and proceed to next iteration.

10. Update the values for the next iteration
}

until 10 - 1 has converged.

11. Once that the aircraft is sized, this analysis can compute its performances over one or more operational ranges different from the design one. 
For classical tube \& wing configurations, MYSTIC incorporates also a certification constraint module ${ }^{23}$ to check if the key CS-25 specifications for large passenger aircraft ${ }^{24}$ are verified. So far, for hybrid aircraft, there are no information on how these specifications may change with the new propulsion chain. Nonetheless, these aspects are relevant in aircraft design as they are driving the design space $^{25}$.

To consider the certification constraints, this work proposes a revision of the CS-25 for the failure cases. Specifically, the One Engine Inoperative condition (OEI), which is requested in the CS-25.119(a), CS-25.121(a) and CS-25.121(b), must be replaced by the One Gasturbine Inoperative (OGI), to ensure that in case one of the two turboshaft cannot be operated, the aircraft is still capable to preserve the required slope. Beside the OGI condition, another failure condition which must be considered is the One Core Inoperative (OCI) condition ${ }^{26}$. In this condition, there is no loss of power and the total amount could be distributed over a reduced number of electric components (see Figure 27 and Figure 28). This means that the OCI case is the sizing condition in terms of power for all the electric components. At this point, two different scenarios can be considered. The first case describes a degraded situation while the second one assumes that the situation is non-critical despite the core failure:

1. The OCI condition is considered an equivalent of the OEI case: the power to be distributed among the functioning electrical components must generate sufficient thrust to match the minimum slope, mimicking the OEI requirements in the CS- 25 document $^{24}$ associated to 4 engines.

2. The OCI is considered as a non-critical flight condition: the thrust level obtained with the remaining functioning electric components is not reduced, leading to an oversizing of a large part of the propulsive chain.

With the sizing and synthesis process well defined, the next step consists in assessing the overall performance of DRAGON for a given reference mission. In a later section, the 2 design philosophies will be compared in terms of overall aircraft sizing and performance to show the impact of a certification decision on the benefits of new technologies.

\section{B. DRAGON performances for a given mission}

In this section, the objective is to compare the benefits of the DEP installed on an aircraft with respect to a reference turbofan aircraft with the same EIS (2035).

\section{Design space definition}

The Top Level Aircraft Requirements (TLAR) of this concept are reported in Table 2: they are the same as the ones of the Airbus A320. To take into account an entry into service in 2035, a set of assumptions on technologies at airframe level is made. In Appendix 3, Table 10 report these variations to be implemented for DRAGON and the reference aircraft. As indicated in section II.C, three 2035 scenarios for electrical components are also detailed in Appendix 3 (Table 9). At airframe level, the tables report results from the IATA study ${ }^{27}$.

\section{Table 2: Top Level Aircraft Requirements for the DRAGON concept}

\begin{tabular}{lrl}
\hline Range & 2750 & $\mathrm{NM}$ \\
Number of passengers & 150 & \\
Mach number & 0.78 & \\
Design payload & 13608 & $\mathrm{~kg}$ \\
Span limit & 36 & $\mathrm{~m}$ \\
Entry Into Service & 2035 & \\
\hline
\end{tabular}

When fixing parameters of the propulsive chain, it is preferable to let the design engineer select the number of electric motors: indeed, it is a design variable used to set the spanwise position of the distributed fans. For this reason, the FPR is fixed, and the number of electric motors is changed in order to cover the desired wing portion. These propulsive parameters are reported in Table 3. From the aeroelastic off-design analysis, one conclusion was that it is better to remove ducted fans in the vicinity of the wing tip. Thus, in Table 3, the usable space for distribution is fixed to $28 \mathrm{~m}$. Basically, considering the maximum wing span of 36 meters, a portion of 2 meters from the wing tip is free of ducted fans. 
Table 3: Parameters of the propulsive chain for the DRAGON concept

\begin{tabular}{lrr}
\hline FPR & 1.25 \\
Number of electric motors & Computed & \\
Number of electric cores & 4 & \\
Usable space for distribution & $28 \quad \mathrm{~m}$ \\
Entry Into Service & 2035 & \\
\hline
\end{tabular}

Another point to consider in the design of DRAGON is the impact of the nacelles on the overall aerodynamics. In MYSTIC, the aircraft drag coefficient $C_{D}$ is computed considering the wetted surfaces and the associated friction coefficient of the various fans. However, the position and the size of electric motors can negatively impact the aerodynamic performances ${ }^{28}$. As the complex $3 \mathrm{D}$ aeropropulsive integration of the ducted fans in DRAGON is not yet optimized, an accurate estimation of the overall aerodynamic efficiency is not yet available. Thus, to be conservative, a penalty of $5 \%$ on the total $C_{D}$ is introduced in MYSTIC to take into account a possible penalty.

Estimation of the Distributed Electric Propulsion benefits

The sizing of DRAGON with MYSTIC is launched considering the previously described hypotheses (moderate scenario evolution for electrical components) and the given reference mission. In parallel, the sizing of a classical turbofan aircraft with 2035 technology is carried out. In the DRAGON sizing process, it must be noted that the OCI condition is set so that a slope of 3\% must be maintained. The reason for this value is that as there are 4 Electrical Core, it has been decided to reproduce the certification requirement associated to 4 engines (CS 25.12124). The results for both vehicles are reported in Table 4 with a DRAGON configuration featuring 26 ducted fans.

Table 4 : Comparison between the DRAGON and the Reference aircraft (2035 technologies, moderate scenario for electrical components)

\begin{tabular}{llccc}
\hline & & DRAGON & Reference A/C & Diff. \% \\
\hline MTOW & {$[\mathrm{t}]$} & 67.87 & 67.67 & 0.29 \\
OWE & {$[\mathrm{t}]$} & 42.69 & 41.48 & 2.94 \\
Wing area & {$\left[\mathrm{m}^{2}\right]$} & 121.44 & 121.79 & -0.29 \\
Cruise lift-to-drag ratio & & 17.19 & 18.53 & -7.24 \\
Fuel consumption & {$[\mathrm{t}]$} & 11.54 & 12.45 & -7.26 \\
\hline
\end{tabular}

As expected, the overall aerodynamic efficiency of DRAGON is well below the one of the reference aircraft. This is due the selected technologies (Table 10) and the 5\% penalty associated to the fan diameter-over-chord ratio. However, the fuel consumption shows a benefit of $7.2 \%$. Then, this benefit is directly associated to the more efficient propulsion system based on transonic DEP. When looking at the key segments of the mission, DRAGON offers a fuel consumption reduction of $6.3 \%$ for the cruise segment while in climb, there is an increase of $5.3 \%$ fuel need. These results are better in line with the overall goal of the distributed propulsion that the ones obtain previously. The main reason for such improvement is the use of a more consolidated turboshaft model. The lower efficiency for the climb phase still needs investigations before pointing out one reason but this point shall not be neglected as overall aircraft efficiency for shorter operational ranges would be affected.

Impact of electrical component technology scenarios on DRAGON

The second analysis that is presented shows the impact of technologies on the DRAGON concept. As reported in Appendix 2, the evolution of electrical component can follow different scenarios. It is then interesting to evaluate the performances of DRAGON considering the most aggressive scenario for 2035 technologies. The results of this sizing loop are summarized in Table 5.

Table 5 : Impact of technologies on the DRAGON concept, considering the base and the best scenario for electric components in 2035 perspectives

\begin{tabular}{llccc}
\hline DRAGON & & Moderate & Significant & Diff. \% \\
\hline MTOW & {$[\mathrm{t}]$} & 67.87 & 61.94 & -8.73 \\
OWE & {$[\mathrm{t}]$} & 42.69 & 38.10 & -10.76 \\
Wing area & {$\left[\mathrm{m}^{2}\right]$} & 121.44 & 112.72 & -7.18 \\
Cruise lift-to-drag ratio & & 17.19 & 17.28 & 0.58 \\
Fuel consumption & {$[\mathrm{t}]$} & 11.54 & 10.12 & -12.38 \\
\hline
\end{tabular}


With this optimistic scenario, there is an impressive reduction in the fuel consumption of about $12 \%$. The explanation is that the evolution of the electrical components has two positive impacts: first, the components are more efficient so there are fewer losses in the transmission of electricity to the fan: the overall propulsion efficiency is directly improved. Besides, the components would be lighter and the overall demand in power would decrease. All these benefits are so important that the lower lift-to-drag ratio with respect to the reference aircraft is no more significant.

Impact of certification philosophy on DRAGON

When detailing the sizing process within MYSTIC, 2 possible options associated to the OCI condition have been identified. In one case, the failure is considered critical and in the degraded condition, the aircraft has to meet certain slope requirements. The other scenario is that it is decided at certification level that a failure of 1 electrical core should not translate into a degraded flight condition. Table 6 reports the results of the sizing process when considering the 2 approaches:

Table 6 : DRAGON performance considering different certification philosophies

\begin{tabular}{llccc}
\hline & & Degraded & Non-critical & Diff. \% \\
\hline MTOW & {$[\mathrm{t}]$} & 67.87 & 80.58 & 18.72 \\
OWE & {$[\mathrm{t}]$} & 42.69 & 53.45 & 25.18 \\
EM number & & 26 & 26 & - \\
Wing area & {$\left[\mathrm{m}^{2}\right]$} & 121.44 & 141.92 & 16.87 \\
Cruise lift-to-drag ratio & & 17.19 & 16.92 & -1.55 \\
Fuel consumption & {$[\mathrm{t}]$} & 11.54 & 13.69 & 18.59 \\
\hline
\end{tabular}

The sizing power requirement for DRAGON is found for the CS-25.121(b) certification specification: at 400ft, a slope of $3 \%$, must be maintained. In the case where the OCI is considered critical, $11.6 \mathrm{MW}$ are required to maintain the correct slope. If the failure must be considered as a non-critical one, the total power required in this point is about 3 times higher. This strongly impacts the masses, as all the electric components are oversized in power, and the empty weight results $25 \%$ higher. Penalties in mass are so important that even if the maximum lift-to-drag ratio is very similar, the fuel consumption is increased of about $19 \%$. From these results it can be concluded that the design philosophy to be applied for the certification of hybrid electric aircraft must be carefully selected in order to converge to a good compromise between technology improvement and safety.

\section{Conclusion}

In the frame of the European Programme Clean Sky 2, ONERA performed in 2019 a second multidisciplinary design and analysis loop on the DRAGON concept in order to mature transonic Distributed Electric Propulsion. Following a review of previous results and other initiatives at industry level on this technology, the initial step consisted in generating a more reliable turboshaft model to verify the basic benefits of Distributed Electric Propulsion. With same analysis tool used by the thermal experts, a turbofan engine to be used for the reference aircraft sizing has been modeled. In this manner, the distribution effects could be better traced when performing performance comparisons at overall aircraft design. Considering DEP as a technology that improves the efficiency of the overall propulsive chain, its integration within a Large Passenger Aircraft is a true challenge. Thus, disciplinary investigations took place in order to identify issues and propose solutions. From an aerodynamic point of view, the 3D computations validated the $2 \mathrm{D}$ shapes and recognized other areas for improvements. However, it is very important to note that the current simulations showed a good overall flow behavior with small areas to be improved. Concerning the wing structure, the shift to a classical hanging solution for the various ducted fans with their associated motors allowed the design of a more efficient structural layout benefitting from the spanwise wing loading through electric motors and inverters. More important, the structural sizing highlighted the penalty in mass if the structure has to be stiffer to limit wing tip deflection. With data derived from the structural sizing, aeroelastic analyses have been completed and showed that there is no flutter risk for DRAGON. Moreover, they indicated that overall aeroelastic dampings are higher when there are no ducted fans in the vicinity of the wing tip. Such important overall layout indication has been subsequently used as an input for the sizing of the aircraft. The last focus before the DRAGON performance assessment has been the revision of the electrical architecture with a focus on reliability. This is the reason why the new architecture features more redundancy: each turboshaft is connected to 2 generators and DC buses are now interconnected so that there a various ways to supply energy. 
In terms of performances for a given reference mission, the results provided by MYSTIC (with the detailed turboshaft database) are very promising. Considering the transport of 150 passengers with a transonic cruise speed over distance of $2750 \mathrm{~nm}$, DRAGON offers a $7 \%$ reduction in fuel burn with respect to an advanced turbofan aircraft (EIS 2035for both aircraft). This result is even more interesting knowing that some margins have been taken and the technology evolution scenario that has been used is the moderate one. To conclude the OAD study, ONERA investigated also different certification philosophies to assess the critical impact at aircraft level that high level choices may have.

In the various studies that have been presented in this paper, a lot of knowledge has been gained by the ONERA team regarding transonic Distributed Electric Propulsion. However, many other points still need to be investigated to make sure that such technology is efficient and viable. The list here below presents various domains that will be studied over the next project period:

- At turboshaft level, it is planned at first to implement more realistic data in GasTurb ${ }^{11}$ so that off-design conditions would be more accurately assessed. Second, there is a large interest in exploring future technologies that could increase the thermal efficiency of such system;

- At aerodynamics level, the overall performance of such distributed configuration will be computed: several methods will be used to find a kind of thrust-drag or power bookkeeping, which is not obvious for such highly coupled engine integration. On top of it, a BLI effect will be quantify, though it is assumed to be weak but not negligible. Last, the design of the "propulsive flap" configuration for low speed based on the final transonic design should be carried out (see Figure 29);

- For structure and aeroelasticity, there is the objective to share a common FE model not only concerning the wing but also the fuselage. About this component, discussion among the design team converged towards the use of a larger fuselage that would offer many assets for the DRAGON concept;

- Regarding the electrical architecture, the design team converged towards a more robust solution that avoid an oversizing of the components through redundancy. The natural next steps consists in completing Fault Tree Analyses to identify possible stoppers and find opportunities for improvements;

- At overall aircraft design, the next activities will focus on the integration of disciplinary knowledge within MYSTIC in order to increase the accuracy of the sizing and synthesis process. Also, given the current results on a mission of $2750 \mathrm{~nm}$, it would be interesting to tailor DRAGON for missions associated to longer ranges as the ones completed by the Airbus A321 XLR.
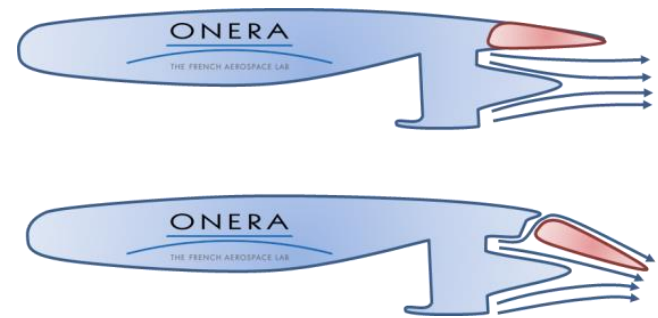

Figure 29 : Illustration of the propuslive flap design to be investigated in the next steps

\section{Acknowledgements}

The authors would like to thank:

- The European Commission for the financial support in the frame of Clean Sky 2 Large Passenger Aircraft Innovative Aircraft Demonstration Platform "LPA IADP" (contract number: CSJU-CS2-GAM-LPA-20142015-01)

- Alessandro Sgueglia for his valuable contribution on the overall aircraft design process through his $\mathrm{PhD}$ with ISAE-Supaero;

- Sébastien Defoort, Carsten Döll, Jean Hermetz and Clément Toussaint from ONERA for their valuable inputs during key workshop on the DRAGON configuration;

- Airbus, DLR, NLR and the University of Delft for the positive exchanges during workshops in the frame of the European Programme Clean Sky 2. 


\section{References:}

$1 \quad$ M. Goldstein, “Does Flight-Shaming Over Climate Change Pose An Existential Threat To Airlines?”, [on line publication] URL: https://www.forbes.com/sites/michaelgoldstein/2019/06/04/does-flight-shaming-over-climate-change-pose-anexistential-threat-to-airlines, [cited 11 June 2019]

2 G. Vittadini and J.-B. Dumont, "What's next ?", Airbus Innovation Days, Toulouse, 2019

3 "Clean Sky 2 - Innovative technologies", [website] URL: https://www.cleansky.eu/innovative-technologies-0, [cited 11 June 2019]

4 “Clean Sky 2 - Large Passenger Aircraft", [website] URL: https://www.cleansky.eu/large-passenger-aircraft, [cited 11 June 2019]

5 K. A. Deere, S. Viken, M. B. Carter, J. K. Viken, D. E. Cox, M. R. Wiese, N. L. Farr, "Computational Component Build-up for the X-57 Maxwell Distributed Electric Propulsion Aircraft", AIAA 2018-1275, 2018

6 M. J. Armstrong, M. Blackwelder, A. Bollman, C. Ross, A. Campbell, C. Jones, P. Norman, "Architecture, Voltage, and Components for a Turboelectric Distributed Propulsion Electric Grid", NASA CR-2015-218440, 2015

7 J. L. Freeman, B. T. Schiltgen, "ECO-150-300 Design and Performance: A Tube-and-Wing Distributed Electric Propulsion Airliner", AIAA 2019-1808, 2019

8 "Aircraft Electrical Propulsion - The Next Chapter of Aviation?", Roland Berger LTD, 2017

9 P. Schmollgruber et al., "Multidisciplinary Exploration of DRAGON: an ONERA Hybrid Electric Distributed Propulsion Concept", AIAA 2019-1585, 2019

10 S. Defoort, M. Méheut, B. Paluch, R. Liaboeuf, R. Murray, D. Mincu, J.-M. David, "Conceptual design of disruptive aircraft configurations based on High-Fidelity OAD process", AIAA Aviation 2018, 2018

11 "Gas turbine performance" [website] URL: http://www.gasturb.de/, [cited 11 June 2019]

12 “CFM, The Power of Flight" [website] URL: https://www.cfmaeroengines.com/engines/leap/, [cited 2 December 2019]

13 T. Grönstedt, K. Kyprianidis, “ Optimizing the operation of the intercooled turbofan engine”, ASME TurboExpo 2010, Glasgow, 2010

14 "Modern gas turbine systems", edited by Peter Jansohn, Woodhead Publishing, 2013

15 T. Grönstedt, M. Irannezhad, X. Lei, O. Thulin, A. Lundbladh, "First and Second law analysis of future aircraft engines", Journal of Engineering for Gas Turbines and Power, Vol 136, 2014

16 J.D. Mattingly, "Elements of Propulsion - Gas turbines and rockets", AIAA Education series, 2002

17 "ONERA ELSA" [website] URL: http://elsa.onera.fr/, [cited 2 December 2019]

18 R. Arnaud, "Étude d'un problème d'optimisation en aéroélasticité avec incertitudes", PhD Dissertation, Mécanique des structures, Ecole Centrale Paris, 2014

19 M. Armstrong, C. Ross, D. Phillips, M. Blackwelder, "Stability, Transient Response, Control, and Safety of a High-Power Electric Grid for Turboelectric Propulsion of Aircraft", NASA CR-2013-217865, 2013

20 A. Sgueglia, P. Schmollgruber, N. Bartoli, O. Atinault, E. Benard, J. Morlier, "Exploration and Sizing of a Large Passenger Aircraft with Distributed Ducted Electric Fans", AIAA 2018-1745, 2018

21 A. B. Lambe and J. R. R. A. Martins, "Extensions to the design structure matrix for the description of multidisciplinary design analysis and optimization processes," Structural and Multidisciplinary Design Optimization, vol. 45, no. 2, pp. $273-284$, 2012.

22 "Devis de masse des avions", AIR 2001/D, Edition N5, Direction Générale de 1’Armement, 1984

23 P. Schmollgruber, N. Bartoli, J. Bedouet, S. Defoort, Y. Gourinat, E. Benard, R. Lafage, A. Sgueglia, "Use of a Certification Constraints Module for Aircraft Design Activities", AIAA 2017-3762, 2017

24 "EASA, CS-25 Large Aeroplanes" [website] URL: https://www.easa.europa.eu/certification-specifications/cs-25-largeaeroplanes, cited [2 December 2019]

25 P. Schmollgruber, "Enhancement of the conceptual aircraft design process through certification constraints management and full mission simulations", Doctoral Thesis ISAE-Supaero, 2018

26 A. Sgueglia, "Sizing and optimisation priorities applied to a Blended Wing-Body with distributed electric ducted fans", Doctoral Thesis ISAE-Supaero, 2019

27 "IATA Technology roadmap - Technical annex", International Air Transport Association, 2014

28 A. T. Wick, J. R. Hooker and C. J. Hardin, C. H. Zeune, "Integrated Aerodynamic Benefits of Distributed Propulsion”, AIAA 2015-1500, 2015 


\section{Appendix 1 - Data for structural analysis}

Table 7 : wing's cross sections description

\begin{tabular}{|c|c|c|c|c|c|}
\hline Section $\mathrm{n}^{\circ}$ & $\begin{array}{c}\text { Span } \\
\text { location } \mathrm{Y} \\
{[\mathrm{m}]}\end{array}$ & Chord $[\mathrm{m}]$ & $\begin{array}{c}\text { Thickness } \\
{[\%]}\end{array}$ & $\begin{array}{c}\text { LES position } \\
{[\%]}\end{array}$ & $\begin{array}{c}\text { TES position } \\
{[\%]}\end{array}$ \\
\hline 1 & 0 & 4.0 & 16.0 & 15.0 & 70.0 \\
\hline 2 & 2.0 & 4.0 & 16.0 & 15.0 & 70.0 \\
\hline 3 & 4.5 & 3.7 & 15.0 & 15.0 & 70.0 \\
\hline 4 & 18.0 & 2.9 & 11.0 & 15.0 & 70.0 \\
\hline
\end{tabular}

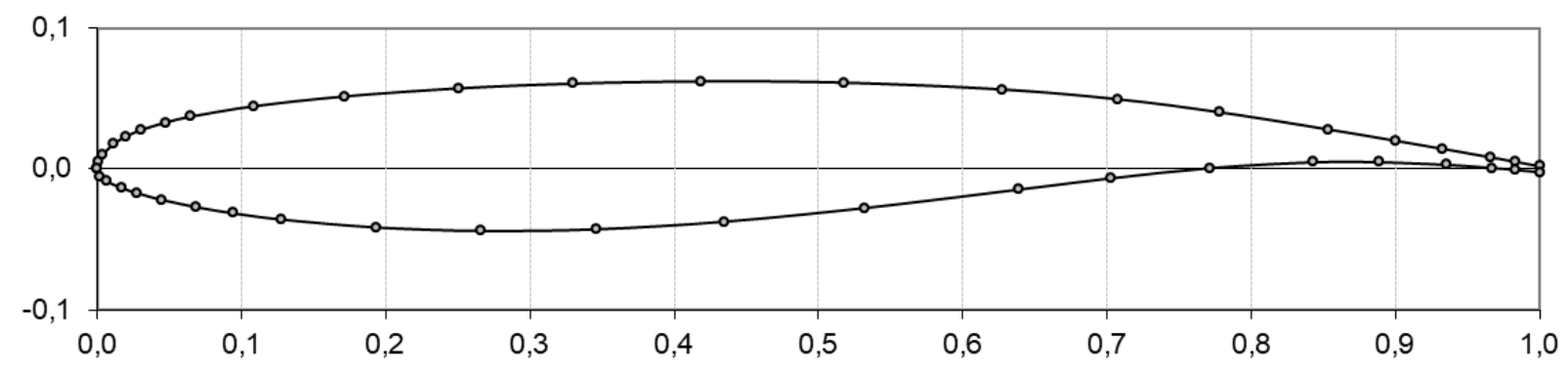

Figure 30 : Example of non-dimensionnal airfoil description

Table 8 : Wing's segments description

\begin{tabular}{|c|c|c|c|}
\hline Segment $\mathrm{n}^{\circ}$ & Section $1\left[\mathrm{n}^{\circ}\right]$ & Section $2\left[\mathrm{n}^{\circ}\right]$ & $\Phi\left[{ }^{\circ}\right]$ \\
\hline 1 & 1 & 2 & 0.0 \\
\hline 2 & 2 & 3 & 25.0 \\
\hline 3 & 3 & 4 & 25.0 \\
\hline
\end{tabular}




\section{Appendix 2 - Technology scenarios}

Table 9: Technology assumptions for components of the Hybrid Electric Distributed Propulsion chain

\begin{tabular}{|l|l|c|c|c|}
\cline { 3 - 5 } \multicolumn{2}{c|}{} & \multicolumn{3}{c|}{ Evolution towards 2035 } \\
\hline \multirow{2}{*}{ Turboshaft } & Pogligible & Moderate & Significant \\
\hline \multirow{3}{*}{ Generator } & Power density $[\mathrm{kW} / \mathrm{kg}]$ & 7 & 8 & 9.5 \\
\cline { 2 - 5 } & Efficiency $[\mathrm{kW} / \mathrm{kg}]$ & 13.5 & 15 & 19 \\
\hline \multirow{2}{*}{ Inverter $/$ Converter } & Power density $[\mathrm{kW} / \mathrm{kg}]$ & 0.9 & 0.95 & 0.98 \\
\cline { 2 - 5 } & Efficiency & 15 & 20 & 25 \\
\cline { 2 - 5 } & Power density $[\mathrm{kW} / \mathrm{kg}]$ & 0.98 & 0.99 & 0.995 \\
\cline { 2 - 5 } & Efficiency & 13.2 & 19 & 25 \\
\hline \multirow{2}{*}{ Electric motor } & Power density $[\mathrm{kW} / \mathrm{kg}]$ & 13.2 & 0.96 & 0.99 \\
\cline { 2 - 5 } & Efficiency & 0.96 & 0.98 & 0.99 \\
\hline Cables & Maximum voltage $[\mathrm{kV}]$ & 2.16 & 3 & 5 \\
\cline { 2 - 5 } & Linear density $[\mathrm{kg} / \mathrm{m}]$ & 1 & 0.8 & 0.5 \\
\hline
\end{tabular}

Table 10 : Characteristics of the Reference aircraft and of DRAGON for EIS 2035

\begin{tabular}{|c|c|c|c|}
\hline & & EIS 2035 Reference Aircraft & EIS 2035 DRAGON \\
\hline Propulsion & $\begin{array}{c}\text { SFC } \\
\text { Mass } \\
\text { Wetted area }\end{array}$ & $\begin{array}{c}-10 \% \text { wrt. LEAP model } \\
\text { (see section II.A) } \\
\text { based on project data } \\
\text { computed as a function of BPR=11 }\end{array}$ & $\begin{array}{c}-10 \% \text { wrt. turboshaft model } \\
\text { (see section II.A) } \\
\text { computed } \\
\text { computed after ducted fan sizing }\end{array}$ \\
\hline Geometry & Wing span & fixed to 36 meters & fixed to 36 meters \\
\hline Aerodynamics & $\begin{array}{c}\text { Morphing wing } \\
\text { Turbulent coating } \\
\text { Shock control } \\
\text { Winglet design } \\
\end{array}$ & $\begin{array}{c}3.3 \% \text { on } \mathrm{L} / \mathrm{D} \\
-5 \% \text { on } \mathrm{CD} 0 \text { wing } \\
-50 \% \text { on } \mathrm{CD} \text { wave } \\
-10 \% \text { on } \mathrm{CD} \text { induced }\end{array}$ & $\begin{array}{c}\text { Not applicable } \\
-5 \% \text { on CD0 wing } \\
-50 \% \text { on CD wave } \\
-10 \% \text { on CD induced } \\
\end{array}$ \\
\hline $\begin{array}{c}\text { Component } \\
\text { Weight }\end{array}$ & $\begin{array}{c}\text { Wing } \\
\text { Fuselage } \\
\text { Landing gear } \\
\text { Pylons } \\
\text { Seats }\end{array}$ & $\begin{array}{l}-10 \% \\
-5 \% \\
-15 \% \\
-5 \% \\
-60 \%\end{array}$ & $\begin{array}{l}-5 \% \\
-5 \% \\
-20 \% \\
-5 \% \\
-60 \%\end{array}$ \\
\hline
\end{tabular}


Appendix 3 - MYSTIC sizing and synthesis process (XDSM format)

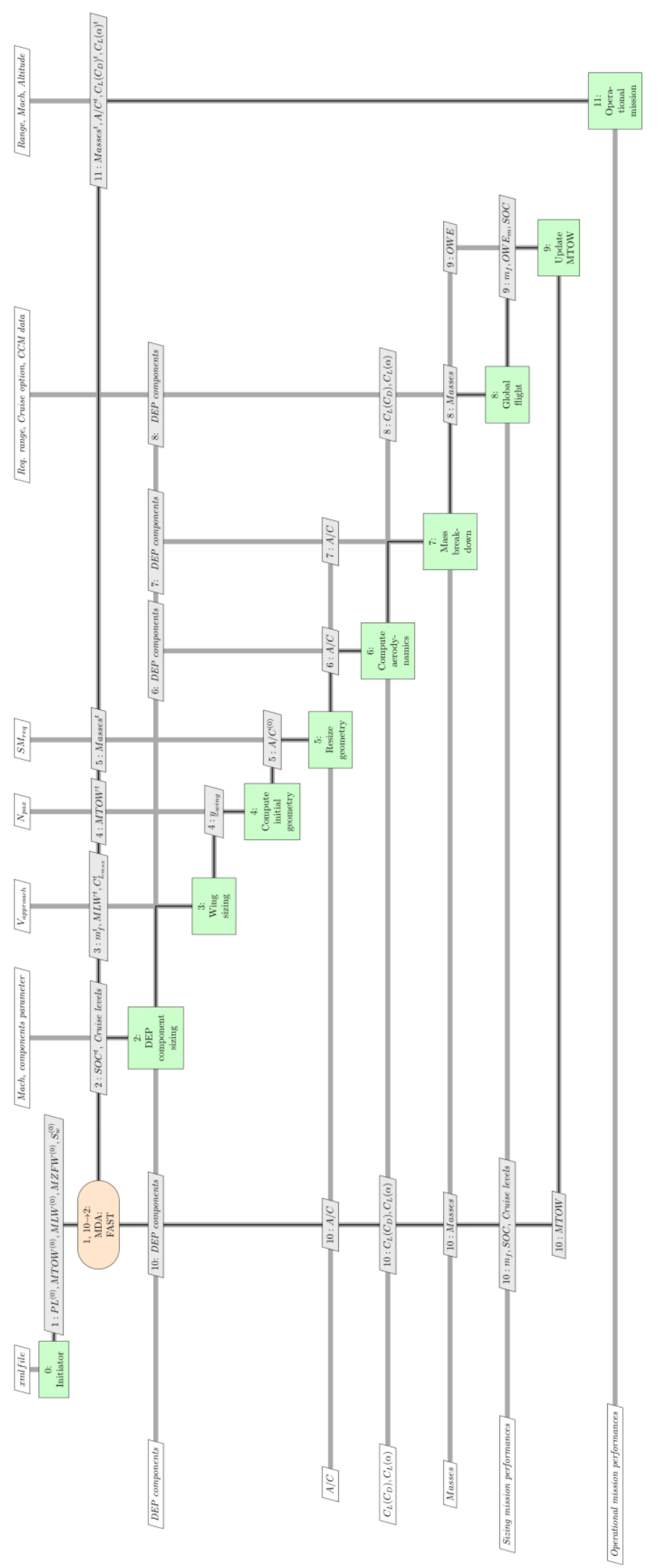

Figure 31: Conceptual design process of DRAGON within MYSTIC (XDSM format)

American Institute of Aeronautics and Astronautics 